\title{
Alternative splicing in endothelial cells: novel therapeutic opportunities in cancer angiogenesis
}

\author{
Anna Di Matteo ${ }^{1 \dagger}$, Elisa Belloni ${ }^{1 \dagger}$, Davide Pradella ${ }^{1 \dagger}$, Ambra Cappelletto ${ }^{2 \dagger}$, Nina Volf ${ }^{2 \dagger}$, Serena Zacchigna ${ }^{2,3^{*+}}$ and \\ Claudia Ghigna ${ }^{1 *+}$ (D)
}

\begin{abstract}
Alternative splicing (AS) is a pervasive molecular process generating multiple protein isoforms, from a single gene. It plays fundamental roles during development, differentiation and maintenance of tissue homeostasis, while aberrant AS is considered a hallmark of multiple diseases, including cancer. Cancer-restricted AS isoforms represent either predictive biomarkers for diagnosis/prognosis or targets for anti-cancer therapies. Here, we discuss the contribution of AS regulation in cancer angiogenesis, a complex process supporting disease development and progression. We consider AS programs acting in a specific and non-redundant manner to influence morphological and functional changes involved in cancer angiogenesis. In particular, we describe relevant AS variants or splicing regulators controlling either secreted or membrane-bound angiogenic factors, which may represent attractive targets for therapeutic interventions in human cancer.
\end{abstract}

Keywords: Alternative splicing; RNA binding proteins, Endothelial cells, Angiogenesis, Vascular biology, Antiangiogenic therapy

\section{Background}

Introduction: from the theory of angiogenesis to an orchestra of alternatively spliced angiogenic genes In the 1970s Judah Folkman revolutionized the field of angiogenesis with his radical idea that tumor growth could be halted by depriving it of blood supply. It all started as a by-product of an investigation originally designed to test the efficacy of haemoglobin-plasma solution as a blood substitute for prolonged extracorporeal perfusion. Folkman was testing whether haemoglobin-plasma solution

\footnotetext{
*Correspondence: zacchign@icgeb.org; arneri@igm.cnr.it

${ }^{+}$Anna Di Matteo, Elisa Belloni, Davide Pradella, Ambra Cappelletto and Nina Volf contributed equally to this work.

${ }^{\dagger}$ Claudia Ghigna and Serena Zacchigna are Co-last authors

${ }^{2}$ Cardiovascular Biology Laboratory, International Centre for Genetic Engineering and Biotechnology (ICGEB), 34149 Trieste, Italy

'Istituto di Genetica Molecolare, "Luigi Luca Cavalli-Sforza", Consiglio Nazionale delle Ricerche, via Abbiategrasso 207, 27100 Pavia, Italy Full list of author information is available at the end of the article
}

sustained viability of dog thyroid glands ex vivo. To prove tissue viability, he implanted mouse tumor cells into dog glands and observed that the neoplastic mass stopped growing after having reached a modest size, but grew rapidly again if transplanted back into a living mouse. He also noticed that retro-transplanted tumors were decorated by a network of tiny blood vessels, which were not present in tumors grown inside the thyroid glands [1]. Later, experiments in the hamster cheek pouch showed that capillary sprouts grew even if tumor cells were separated from the host stroma by a porous filter, suggesting the existence of an active humoral factor capable of driving tumor neovascularization (also named angiogenesis) [2, 3]. This factor was isolated by Folkman and initially named tumorangiogenesis factor, TAF. It could be purified from human and animal tumors, as well as from the placenta, and showed remarkable mitogenic activity toward endothelial cells (ECs) in multiple assays [2-4]. This was the first 
evidence that tumor growth is always accompanied by new blood vessel formation and paved the way to the idea of blocking angiogenesis to halt tumor growth. In its original assumption, the concept of anti-angiogenesis would prevent new vessel sprouts from penetrating into an early tumor and keep it in an avascular and dormant state, in which it cannot exceed 2-3 mm size [5]. While this concept was initially widely criticized, its potential efficacy in treating cancer started to emerge a few years later, when Folkman teamed up with his students and monitored the grow of cancer cells when implanted into either the avascular anterior chamber of the eye or the iris, which contains abundant blood vessels. Avascular implants in the anterior chamber barely grew and soon became dormant. In contrast, the same tumors grew 4000-fold faster in the vascularized iris. This clearly demonstrated that tumor growth depends on blood supply and tumor dormancy is caused by lack of vascularization and not by cell cycle arrest or immune control, as previously believed [6]. Discovery of TAF triggered the search for numerous angiogenic molecules, including vascular endothelial growth factor (VEGF), fibroblast growth factor (FGF), angiogenin, and many others [7].

Over the years, a more complex situation has emerged, and the original names (i.e. VEGF or FGF) are currently used to indicate families of proteins, each one existing in multiple splicing isoforms. It has also become clear that members of the same family, but also alternative splicing (AS) variants of the same protein, can elicit either proor anti-angiogenic activities. Their relative abundance in cancer significantly contributes to the effective formation of new blood vessels and thus AS represents an attractive target for the development of innovative therapies.

\section{Alternative splicing}

In eukaryotic cells, intron removal from primary transcripts (pre-mRNAs) by splicing is an obligatory step before mature mRNAs are transported into the cytoplasm for their translation (Fig. 1a). Splicing is realized in the nucleus by a complex and dynamic molecular machinery, the spliceosome, which recognizes short consensus motifs close to the exon-intron and intron-exon junctions: the $5^{\prime}$ and the $3^{\prime}$ splices sites, the branch point, and the polypyrimidine tract [8] (Fig. 1a). These sequences are bound by spliceosome components (such as snRNPU1, snRNPU2, SF1, U2AF65, and U2AF35), which undergo multiple conformational rearrangements, leading to splicing catalysis (Fig. 1b).

While in constitutive splicing an exon is always included in the mature mRNA, AS is characterized by intron retention, exon skipping, usage of alternative $5^{\prime}$ or 3 ' splice sites, and mutually exclusive exons (Fig. 1c). In this way, AS generates multiple mRNAs and, as a consequence, different proteins with diverse structure, function, stability, and sub-cellular localization [9]. AS correlates with organism complexity, affecting 95\% of human protein-coding genes $[10,11]$ and only $25-60 \%$ of Drosophila melanogaster and Caenorhabditis elegans genes, respectively [12-14].

Alternatively spliced mRNAs frequently display a tissuespecific expression [11] and encode for specialized proteins involved in development, differentiation and maintenance of tissue homeostasis [15]. AS often affects domains involved in protein-protein interaction, suggesting its crucial role in controlling connected signaling cascades [15].

Splicing signals (for example 3' splice sites) are often short and degenerated. The intrinsic weakness of these motifs determines their low affinity for spliceosome components. This, in combination with auxiliary sequences that are located either within exons or in the adjacent introns, creates the opportunity to realize AS schemes. Auxiliary splicing signals are recognized by RNA binding proteins (RBPs), which either stimulate (enhancers) or inhibit (silencers) spliceosome assembly on the pre-mRNA [16] (Fig. 1d). The majority of the splicing enhancers are purine-rich motifs and are bound by Serine-Arginine-rich (SR) proteins [17]. On the contrary, splicing silencers are diverse in sequence and they are mainly bound by heterogeneous nuclear ribonucleoproteins (hnRNPs) [18]. Similar to transcription regulatory sequences, splicing enhancers and silencers are often clustered on the pre-mRNA. Consequently, several SR proteins and hnRNPs act in either synergistic or antagonistic manner. For example, SR proteins can block the binding of hnRNPs to a nearby silencer sequence and thus inhibit their negative effect on splicing (Fig. 1d). Therefore, the relative levels of SR proteins and hnRNPs determine the outcome of the AS reaction. While SR proteins are ubiquitously expressed, a few splicing regulatory factors (SRFs) display a more restricted pattern of expression, thus contributing to tissue-specific gene expression programs [15]. Finally, reading of the "splicing code" depends on multiple elements that can mask splicing signals, including secondary structures in the premRNA [19], chromatin organization, epigenetic modifications [20], and RNA pol II elongation rate [21].

AS dysregulation has emerged as an important genetic modifier in tumorigenesis [22]. Mutations in splicing sequences and/or altered expression of SRFs are frequent in tumors [23]. A number of SRFs behave as bona fide oncogenes $[24,25]$, whereas others act as tumor suppressors $[26,27]$. Since a specific SRF controls hundreds (if not thousands) of target genes, its aberrant expression in cancer cells results in global changes of AS signatures, potentially driving either oncogene activation or inhibition of tumor suppressors [22, 28]. Transcriptome sequencing data from clinical samples indicate that several AS errors are cancer-restricted and particularly relevant for the 


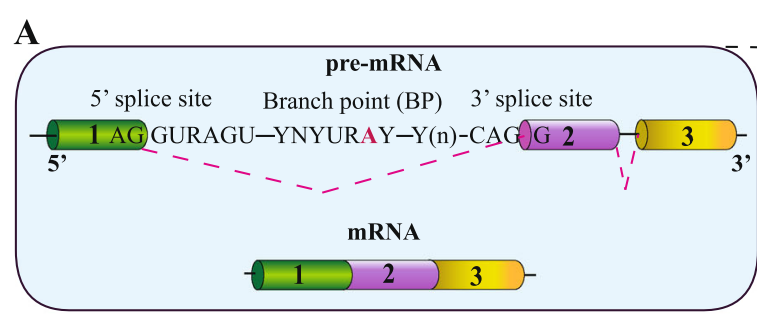

$\mathbf{B}$
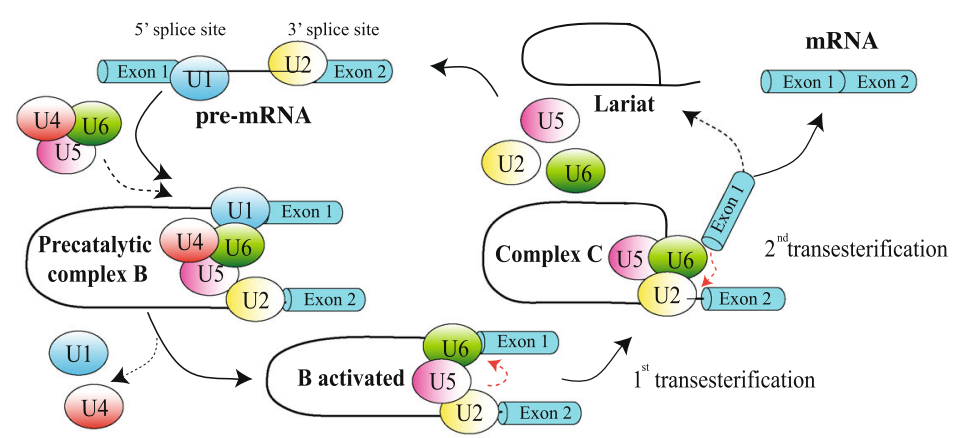

C
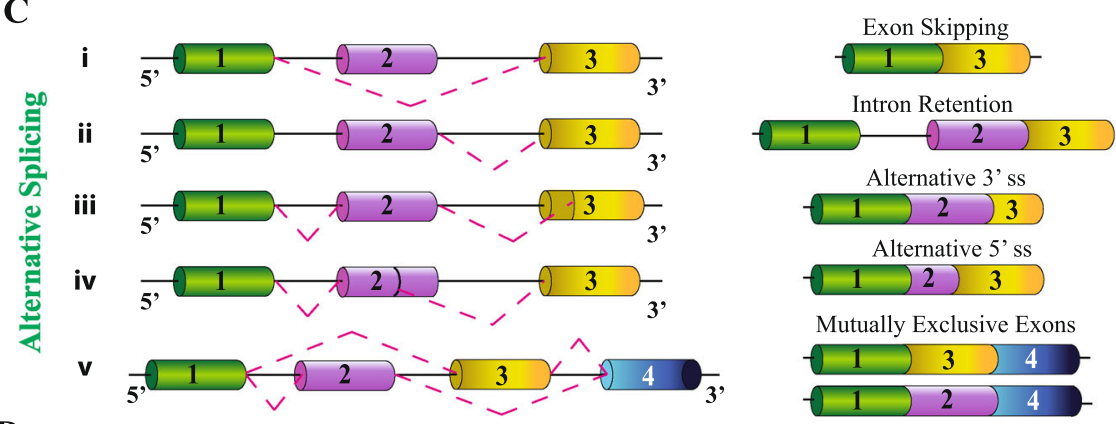

D
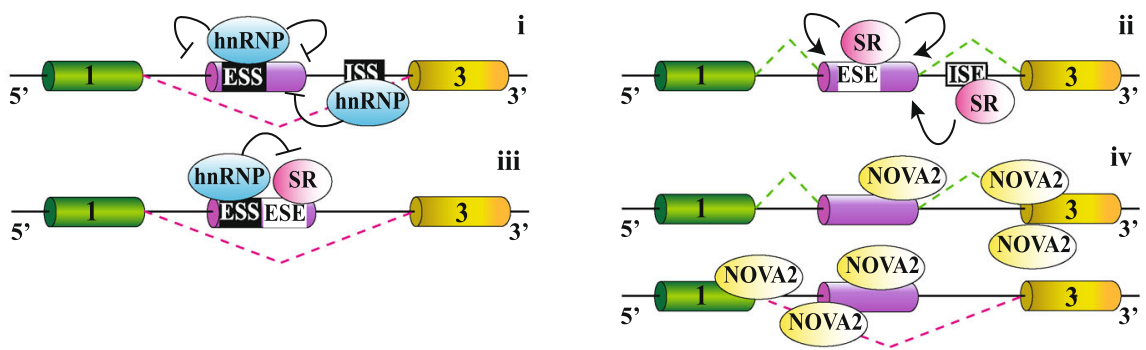

Fig. 1 Splicing reaction and its regulation. a) Splicing, which occurs in the nucleus of eukaryotic cells, required cis-acting sequences located in the pre-mRNA at the exon/intron and intron/exon junctions: the 5' splice site, the branch point or BP, the polypyrimidine Y tract and 3' splice site. $\mathrm{R}=$ purine; $\mathrm{N}=$ any nucleotide; $\mathrm{Y}=$ pyrimidine. b) Splicing involved two consecutive transesterification reactions carried out by the spliceosomal machinery, which is composed by five small nuclear ribonucleoproteins (U1, U2, U4, U6, and U5 snRNPs). The different complexes formed by snRNPs, pre-mRNA and a large number of proteins (not indicated) are depicted. The final product of the splicing reaction is the mature mRNA in which exons are ligated together, whereas intron is released in the form of a looped structure (the lariat). Thin black lines=introns; blue cylinders= exons. c) Different types of AS reaction: (i) exon skipping; (ii) intron retention; (iii) alternative 3' splice sites (ss); (iv) alternative 5' splice sites (ss); (v) mutually exclusive exons. d) AS regulation requires the combined action of trans- and cis-acting elements. (i) Generally, hnRNPs by binding intronic or exonic splicing silencers (ISS or ESS) directly prevent the recognition of the regulated exon by the spliceosomal machinery (red dashed lines). (ii) On the contrary, exonic or intronic splicing enhancers (ESE or ISE) are bound by SR factors able to stimulate spliceosome assembly on 5' and 3' splice sites (blue dashed lines). (iii) hnRNPs can also polymerize along the exon and displace ESE-bound SR factors, thus preventing exon recognition. (iv) Differently, other SRFs (like NOVA2) are able to promote or repress exon recognition depending on the location of their binding sites on the pre-mRNA. For example, NOVA2 stimulates exon skipping (red dashed lines) when bound to exonic or upstream intronic YCAY (Y= pyrimidine) clusters, while it promotes exon inclusion (green dashed lines) when associated to downstream intronic motifs 
diagnosis, prognosis and targeted therapy of multiple cancer types $[29,30]$.

\section{Main text}

\section{Genome-wide AS changes in ECs}

Genome-wide studies have revealed that AS acts in a specific and non-redundant manner to influence EC response to diverse stimuli [31, 32]. For example, blood flow determines different levels of shear stress in ECs depending on the anatomical site, as well as on pathological conditions (i.e. atherosclerosis, aneurysms) [33, 34]. ECs sense and convert this mechanical stimulus into an intracellular response through mechanosensor receptors expressed on EC surface. A paradigmatic example of AS regulation by shear stress refers to specific isoforms of the extracellular matrix (ECM) protein fibronectin (EDA-FN and EDB-FN), which are expressed in pathological conditions, but absent in the normal quiescent vasculature [35], as discussed later. More recent RNA-seq analysis further demonstrated a more extensive role of AS in endothelial response to altered hemodynamics, which affects multiple factors implicated in vascular remodeling, such as PECAM1, YAP1, and NEMO [31].

Another important stimulus able to globally remodel EC transcriptome is hypoxia, a condition in which cells are deprived of oxygen, as happens in the center of a tumor mass [36]. Both tumor and stromal cells release pro-angiogenic factors that stimulate the formation of immature, disorganized, and leaky vessels [37], further enhancing the hypoxic condition of the tumor microenvironment [38]. The hypoxia inducible transcription factors HIF-1 and HIF-2 activate a gene expression program required for EC adaptation to insufficient oxygen supply [39]. Since HIF-1 and HIF-2 act as transcription factors, previous transcriptome analyses of hypoxic ECs have been mainly focused on changes in mRNA steadystate levels and proteomic profiling [36, 40], whereas very few studies have investigated the global impact of AS regulation during oxygen deprivation. Splicingsensitive microarrays applied to human umbilical venous ECs (HUVECs) exposed to hypoxic conditions identified genome-wide AS changes [41, 42], affecting factors involved in cytoskeleton organization (CASK, ITSN1, SPTAN1, and TPM1), cell adhesion (NRP1 and ROBO1), apoptosis $(L A R P 6)$ and universal regulators of gene expression (SH3KBP, RPP9, ZNF589, HMGA2, CELF1, and $M A X)$. These initial studies used microarrays, which are limited in the number and type of AS events that could be detected [43]. RNA-seq approaches have more recently allowed the identification of robust hypoxiainduced AS programs in cancer cells [44, 45], although detailed AS signatures in hypoxic ECs are still missing and will require further investigations.

\section{AS isoforms acting on the extracellular space during physiological and tumor angiogenesis}

Numerous proteins generated by AS affect EC biology. Here, we focus on events affecting proteins that are either membrane-bound or secreted, and thus represent putative targets for anti-angiogenic therapy (summarized in Table 1 and Fig. 2). A more exhaustive list of AS isoforms potentially modulating cancer angiogenesis is provided in Supplementary Table 1 (Additional files 1 and 2).

\section{VEGF-A}

Among the growth factors, receptors, cytokines and enzymes controlling angiogenesis [108], VEGF-A is the main pro-angiogenic cytokine. It mainly binds its receptors (VEGFR1 and VEGFR2) exposed on EC surface [109].

AS regulation of VEGFA is paradigmatic. In particular, the differential usage of proximal and distal 3' splice sites in exon 8 generates isoforms with different Cterminal domains and characterized by opposite properties, respectively being "pro-angiogenic" $\left(V E G F-A_{x x x} a\right.$, where $\mathrm{xxx}$ indicates the position of the amino acid residue in a specific isoform) or "anti-angiogenic" (VEGF$\left.A_{x x x} b\right)$ (Fig. 2a). These isoforms can also differ for their heparin-binding affinity, a region encoded by exons 6 and 7 [110]. While VEGF- $A_{x x x} b$ variants have not been detected in ECs, two pro-angiogenic AS variants are present in these cells, including VEGF- $\mathrm{A}_{165} \mathrm{a}$, and VEGF$\mathrm{A}_{189} \mathrm{a}$ (corresponding to the mouse proteins VEGF$\mathrm{A}_{164} \mathrm{a}$, and VEGF-A $\mathrm{A}_{188} \mathrm{a}$ ) [111]. Overexpression of these variants affects $\mathrm{EC}$ proliferation, adhesion, migration and the integrity of EC monolayers, as they all activate VEGF R2, although at a different extent [112]. Remarkably, VEGF- $A_{188}$ a is highly expressed in ECs from lung but not in tumor ECs, while VEGF- $\mathrm{A}_{164}$ a increases in tumor versus normal ECs [47], in line with the pro-angiogenic phenotype of ECs in cancers.

Currently known VEGFA splicing regulators include members of SR protein family (i.e. SRSF1, SRSF2, SRSF5, and SRSF6) [113-115] and the serine-arginine protein kinase 1 (SRPK1) [116]. Phosphorylation of SRSF1 by SRPK1 determines SRSF1 nuclear localization that in turn promotes the usage of the proximal 3' splice site and the production of the pro-angiogenic isoform VEGF-A $A_{165}$ a [117]. Inhibition of SRPK1 reduces angiogenesis in vivo, setting it as a relevant target for antiangiogenic therapy [48]. More recently, the circular RNA cirCSMARCA5 has been identified as a sponge for SRSF1, controlling the ratio of VEGF-A pro- and antiangiogenic isoforms in glioblastoma multiforme [118]. Moreover, SRSF2 and SRSF6, which both favor VEGF$\mathrm{A}_{\mathrm{xxx}} \mathrm{b}$ expression, are known to be regulated by the noncanonical WNT [119] and TGF $\beta 1$ pathways [46]. Finally, RBM10, an RBP modulated in cancer cells by epigenetic modifications of its promoter, has been associated with 
Table 1 Alternatively spliced isoforms of angiogenesis-related genes and their potential use for anti-angiogenic therapy

\begin{tabular}{lll}
\hline GENE & AS variant & Relevance in cancer angiogenesis \\
\hline VEGF-A & VEGF-Axxxa & Expression/function \\
& Overexpressed by a wide variety of human tumors. Pro-angiogenic func- \\
& tion, produced by both cancer cells and ECS [46].
\end{tabular}

VEGF-Axxxb

VEGF receptors (VEGFRS)

SVEGFR1

SVEGFR2

Neuropilins (NRPS)

SNRP1

NRP 1- $\triangle 7$

NRP1- $\triangle \mathrm{E} 4, \mathrm{NRP} 1-\triangle \mathrm{E} 5$

$\mathrm{S}_{9} \mathrm{NRP} 2$

Membrane-bound NRP2 variants

FGFRIIIb

Fibroblasts growth factor receptors (FGFRs)

VASH1A

VASH1B

VASH2-355aa

VASH2-290aa

ANG1-0.7, - 0.9 and $-1.3 \mathrm{~kb}$

$\mathrm{ANG}_{443}$

\section{Expression/function}

Anti-angiogenic function, generally downregulated in cancer [46]; not detected in normal or tumor ECs [47].

Examples of potential use for therapy

SRPK1 inhibitors to promote AS into VEGF-Axxxb isoform [48]. Compounds blocking spliceosome machinery (Spliceostatin A, FR901464) [49, 50].

Expression/function

Anti-angiogenic function, inhibits VEGF signalling in ECs [51].

Controversial role in cancer [52-54].

Examples of potential use for therapy

Morpholino oligonucleotides to promote AS into sVEGFR1 [55].

Expression/function

Decreases lymphangiogenesis. Downregulated in neuroblastoma patients [56].

Expression/function

Soluble decoy receptor. Anti-angiogenic function [57-59].

Examples of potential use for therapy

Overexpression of sNRP1 to prevent VEGF signalling [60].

Expression/function

Altered glycosylation. Anti-angiogenic function [61].

Expression/function

Altered glycosylation and endocytic trafficking [62].

Expression/function

Decoy function [63].

Expression/function

Differentially activate signalling pathways [58].

Expression/function

Expressed by epithelial tissues [64]. Pro-angiogenic function [65, 66]. Examples of potential use for therapy

Anti-FGFR2-IIIb-Specific Antibody (GP369) [67].

Expression/function

Expressed in mesenchymal tissues [64] and primary ECs [68].

Expression/function

Possible decoy function [69].

Expression/function

Hyper-activation of the signalling pathway [69].

Expression/function

Differential impact on receptor internalization and downstream signalling. C3 implicated in oncogenesis [70].

Expression/function

Deletion affects downstream signalling [71].

Expression/function

Anti-angiogenic-function. Expressed by ECs [72]

Examples of potential use for therapy

Overexpression of VASH1A [72].

Expression/function

Expressed by ECs. Promotes the normalization of tumor blood vessels [72].

Examples of potential use for therapy

Overexpression of VASH1B [72].

Expression/function

Expressed by ECs [73]; unknown function.

Expression/function

Anti-angiogenic function [73].

Expression/function

Differentially activates TIE2 pathway [74]

Expression/function

Expressed in primary ECs and non-endothelial tumor cell lines. It antagonizes TIE2 signalling during tumorigenesis and inflammation [75].

Expression/function

Differentially activates TIE2 signalling [76]. 
Table 1 Alternatively spliced isoforms of angiogenesis-related genes and their potential use for anti-angiogenic therapy (Continued)

\begin{tabular}{|c|c|}
\hline$\overline{\text { GENE }}$ & AS variant \\
\hline Fibronectin (FN) & EDA/EDB-FN \\
\hline Tenascin C (TNC) & Large TNC variants \\
\hline \multirow[t]{2}{*}{ SLIT2 } & Slit2-WT \\
\hline & Slit2- $\Delta \mathrm{E} 15$ \\
\hline \multirow[t]{2}{*}{ PECAM1 } & PECAM1-FL, $\Delta 12, \Delta 13, \Delta 14, \Delta 15, \Delta 14 \& 15$ \\
\hline & SPECAM 1 \\
\hline \multirow[t]{2}{*}{ CD146 } & shCD146 \\
\hline & $\lg C D 146$ \\
\hline CD44 & $\mathrm{CD} 44 \mathrm{v} 6$ \\
\hline
\end{tabular}

\section{Expression/function} Relevance in cancer angiogenesis

Expressed during embryonic and tumor angiogenesis. EDA-FN plays a role in vascular remodelling and prevents vascular oxidative stress in diabetic conditions [77, 78].

Examples of potential use for therapy

Drug delivery [79].

\section{Expression/function}

Expressed in pathological tissues undergoing active remodelling Favour cell migration [80].

Specific spliced variants or single AS domains are associated with different tumor types [80] types; FNIII C-bearing TNC isoform is highly expressed in brain and lung tumors, associated with tumor stroma [81]. Examples of potential use for therapy

TNC antibodies to deliver cytotoxic molecules, recognizing the AS domains $A 1$ to $D$ of the large isoform of TNC. Aptamer TTA1 [82].

Expression/function

Expressed and released by tumor cells. Reduces EC permeability [83].

\section{Expression/function}

Expressed and released by normal cells. Reduces EC permeability and plays a role in vessel normalization [83].

Expression/function

PECAM1-FL is the major form of PECAM-1 in human tissues and ECs [84, 85]. Different isoforms bear different signalling potential, thus impacting angiogenesis process [86].

Expression/function

Possible function in regulating PECAM1-mediated cellular interactions [87].

Expression/function

Promotes EC proliferation, migration and adhesion [88]

Expression/function

Promotes EC tube formation and stabilization [88].

Expression/function

Controls EC migration, sprouting and tube formation, acting as a VEGF R2 co-receptor for VEGF-A [89].

Examples of potential use for therapy

CD44v6 blockage by soluble peptides [90], humanized monoclonal antibody [91], shRNA [92], miRNA [93], or antisense oligonucleotides [94]. CAR-T cells against CD44v6+ cancer cells (ClinicalTrials.gov: NCT04427449 [95]).

Endoglin (ENG) _ L-endoglin

S-endoglin

Insulin receptor (IR)

Tissue factor (TF)

asTF

fITF
Expression/function

Interacts with TGF $\beta$ type I receptors ALK1, enhancing its-mediated pathway $[96,97]$.

\section{Expression/function}

Interacts with TGF $\beta$ type I receptors ALK5, stimulating ALK5 pathway. Associated with altered pulmonary angiogenesis [98]. It is induced by senescence and able to contribute to NO-dependent vascular homeostasis.

\section{Expression/function}

Pro-proliferative function; overexpressed in tumor vasculature [99]

\section{Expression/function}

Soluble factor, highly expressed in advanced stages of several human cancers $[100,101]$. Stimulates tumor growth, angiogenesis and metastasis [102].

\section{Examples of potential use for therapy}

Antibody drug conjugate of TF and monomethyl auristatin E [103].

\section{Expression/function}

Highly expressed in several types of cancer. Involved in cancer-related thrombosis, tumor growth and metastasis [104].

Examples of potential use for therapy

Anti-flTF antibody $10 \mathrm{H} 10$ [105].

\section{Expression/function}

Soluble form of LICAM, released by ECS. Promotes EC tube formation and neovascularization. Overexpressed in the ovarian cancer vasculature; associated with tumor vascularization [106].

\section{Expression/function}

Highly expressed in tumor vasculature several types of cancer. Proangiogenic function [107]. 


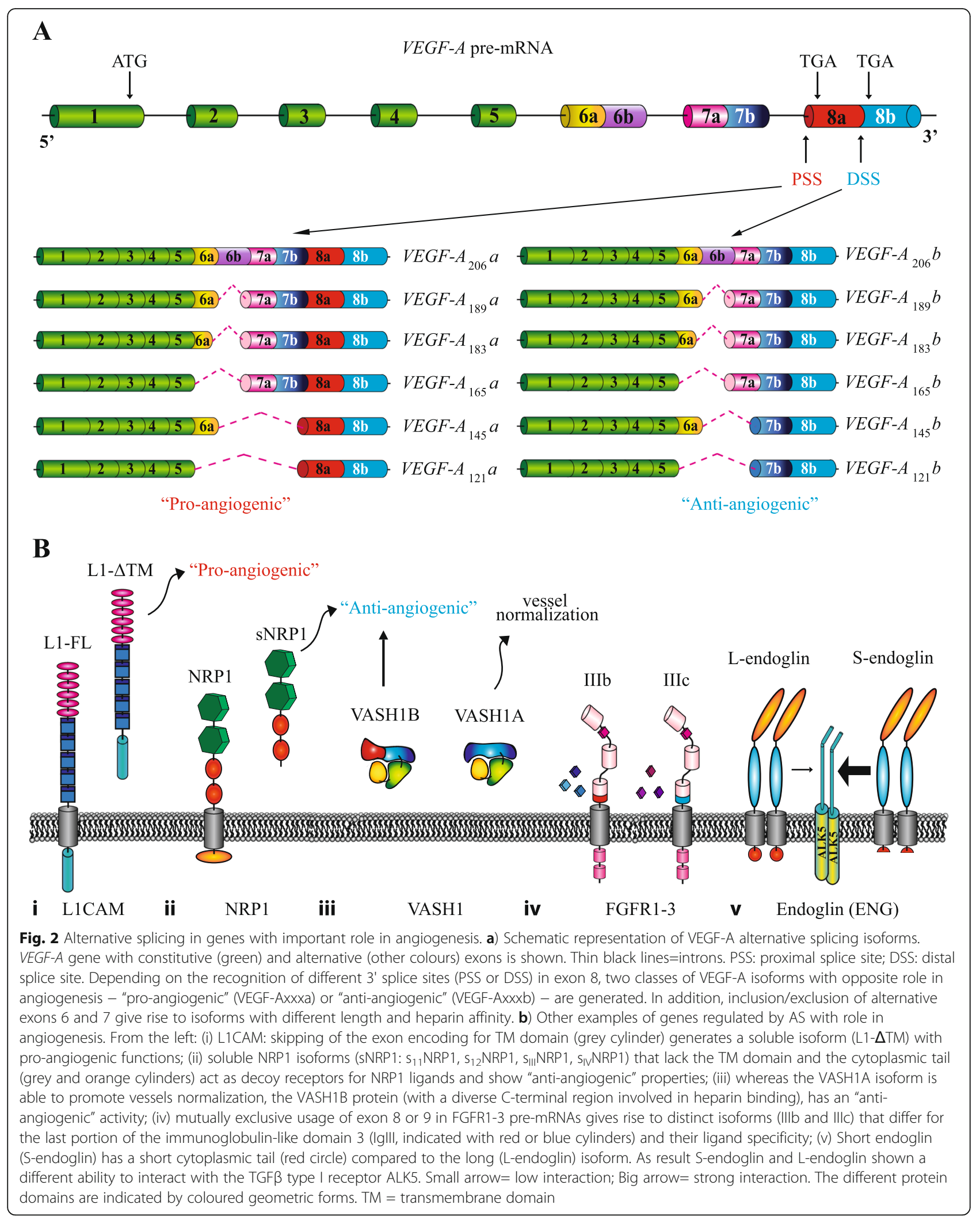


the production of the VEGF- $\mathrm{A}_{165 \mathrm{~b}}$ anti-angiogenetic variant [120].

\section{VEGF receptors (VEGFRs)}

VEGFRs are tyrosine kinase receptors mediating VEGF signaling during both development and disease [121]. The family comprises three members, VEGFR1, VEGF R2 and VEGFR3, which exist as either membrane bound or soluble molecules, depending on AS. Soluble (s) isoforms of VEGFR1 (encoded by the FLT1 gene) derive from the usage of alternative polyadenylation signals after partial retention of intron 13 (sVEGFR1-i13) or 14 (sVEGFR1-i14) or the terminal exons $15 \mathrm{a}$ and $15 \mathrm{~b}$ (sVEGFR1-e15a/-e15b) [122]. All sVEGFR1 isoforms have an anti-angiogenic role, by either sequestering VEGF-A or forming inactive heterodimers with other VEGF receptors, thereby preventing downstream signaling [51].

The mechanisms leading to sVEGFR1 production in ECs are not fully elucidated. A role for hnRNP D has been described in HUVECs, in which its overexpression significantly decreases soluble/membrane-VEGFR1 ratio [123]. In addition, JMJD6 is involved in splicing regulation of FLT1 [124], by interacting with the spliceosome component U2AF65, and thus stimulating the production of the membrane-bound isoform. Under hypoxic conditions, the interaction between JMJD6 and U2AF65 is inhibited and this generates the sVEGFR1-i13 variant [124]. A recent work suggests that the U2AF65/JMJD6 circuit could regulate the ECM enzyme heparanase to stimulate sVEGFR1 release from the ECM [125]. In cancer cells, VEGF-A ${ }_{165}$ a cooperates with the transcription factor SOX2 and SRSF2 to promote sVEGFR1-i13 expression [126]. An additional layer of complexity is provided by the observation that VEGFR2 (encoded by the KDR gene) also exists in a soluble form (sVEGFR2), generated by the retention of a part of intron 13 [127]. By binding to VEGF-C, sVEGFR2 inhibits the activation of VEGFR3 during lymphatic EC proliferation [127].

\section{Neuropilins (NRPs)}

NRP1 and NRP2 are cell surface glycoproteins that act as co-receptors for different factors, such as VEGF and semaphorins [128]. NRP1 interacts with VEGFR1 or VEGFR2 in ECs, whereas NRP2 plays an important role in lymphangiogenesis thanks to its ability to dimerize with VEGFR3 [128]. NRP1 pre-mRNA can be spliced in different isoforms. Some of these AS isoforms $\left(\mathrm{s}_{11} \mathrm{NRP} 1\right.$, $\mathrm{s}_{12} \mathrm{NRP} 1, \mathrm{~s}_{\mathrm{III}} \mathrm{NRP} 1, \mathrm{~s}_{\mathrm{IV}} \mathrm{NRP1}$ ), which lack the transmembrane domain (TM) and the cytoplasmic tail [57-59], are soluble proteins that act as decoy receptors by sequestering NRP1 ligands, thus exerting anti-angiogenic functions [57] (Fig. 2b). Another NRP1 splice variant (NRP1- $\Delta 7$ ) derives from the usage of an alternative $5^{\prime}$ site in exon 11 leading to the deletion of 7 amino acids [61].
Such deletion impairs glycosylation of the NRP1- $\Delta 7$ variant that fails to be internalized in the intracellular vesicles upon VEGF-A binding as well as to activate downstream pathways, thus acting as an anti-angiogenic protein [61]. More recently, other variants lacking exon 4 (NRP1- $\Delta$ E4) or $5(\mathrm{NRP} 1-\triangle \mathrm{E} 5)$ have been identified and characterized by altered glycosylation and endocytic trafficking, resulting in loss of cell migratory and invasive capacity [62].

NRP2 also exists as either membrane-bound or soluble isoforms, generated through AS. The soluble variant $\mathrm{S}_{9} \mathrm{NRP} 2$ results from intron 9 retention, which produces a truncated protein, exerting a decoy function by sequestering VEGF-C and inhibiting oncogenic VEGF-C/NRP2 signaling [63]. Membrane-bound NRP2 in turn exists in multiple AS forms, which differ in their cytosolic domain, suggesting diverse intracellular signaling pathways [58].

\section{Fibroblasts growth factor receptors (FGFRs)}

AS controls FGFR function at multiple levels [69]. For instance, the mutually exclusive usage of either exon 8 or exon 9 in FGFR1-3 pre-mRNAs, encoding for the last portion of the immunoglobulin-like domain 3 (IgIII), generates the so called IIIb and IIIc isoforms, having different ligand specificity [129] (Fig. 2b). ECs mainly express the FGFR1IIIc, FGFR2IIIc, and FGFR3IIIc isoforms of FGFRs [68]. Intriguingly, an unbalance of FGFR-III splicing isoforms has been implicated in tumor angiogenesis and metastasis [130-133].

Among the RBPs influencing IIIb/IIIc isoform ratio are ESRP1, ESRP2, hnRNP $F / H / K / M$, RBM4, hnRNP A1, PTBP1, and PTBP2 [134-136]. An additional layer of complexity is also added by the epigenetic status of FGFR1-3 genes, which can influence not only receptors expression [137], but also their isoform composition through splicingspecific histone modification patterns affecting the recruitment of PTB splicing factors [20].

Moreover, AS sustains the production of soluble variants through removal of the TM domain encoding exon [69]. Another AS event, resulting in the exclusion of exons encoding for FGFR auto-inhibitory domain, promotes the formation of hyper-activated receptors [69], whereas the inclusion of distinct C-terminal sequences in FGFR2 results in a differential composition in tyrosine residues, important for receptor phosphorylation [70]. Finally, exclusion of six nucleotides coding for the valine and threonine motif in the intracellular juxtamembrane region of FGFR1-3, impairs the binding of effector proteins, thus altering downstream signaling [71].

\section{Vasohibins}

Vasohibin-1 (VASH1) is an angiogenic inhibitor released by ECs in response to pro-angiogenic molecules [138]. Its AS produces two variants: VASH1A (full-length), and VASH1B (lacking exons 6-8) [72], which differ in their C- 
term domains (involved in heparin binding) and have opposite effects on ECs (Fig. 2b). While VASH1B inhibits angiogenesis, VASH1A promotes the normalization of tumor blood vessels [72], defined as the transient reduction (in structure and function) of the tumor vessels abnormalities. Vessel normalization is a novel concept in antiangiogenesis targeting approaches. Indeed, by increasing blood perfusion and delivery of drugs, the normalization of the tumor vasculature could improve the responsiveness to chemotherapy, radiotherapy and immune cell therapy [139].

AS of Vasohibin-2 (VASH2) generates multiple polypeptides of different length. In ECs, the full-length variant, composed of 355 amino acids, is the most represented, while another isoform of 290 amino acids exerts antiangiogenic activity [73].

\section{Angiopoietins}

Angiopoietins (ANG1-4) are important modulators of vascular function by binding to TIE receptors. ANG1 is an agonist of TIE2, the activation of which promotes blood vessel stability, while ANG2 can act either as an antagonist or a weak agonist of TIE2, thereby regulating ANG1 activity with variable effects, depending on the context [140]. AS of ANG1 gives rise to three shorter variants (0.7, 0.9 and $1.3 \mathrm{~kb}$ long), which show different capacity to phosphorylate TIE2 receptor, thereby regulating ANG1 function [74]. ANG2 ${ }_{443}$, generated by skipping of exon 2, binds the TIE2 receptor and it is expressed in primary ECs and in non-endothelial tumor cell lines [75]. This isoform, however, does not induce TIE2 phosphorylation and thus is an antagonist of TIE2 signaling during tumorigenesis and inflammation [75]. Finally, ANG2B, which derives from the inclusion of exon $1 \mathrm{~B}$, also modulates ANG2 activity and thus TIE2 signaling [76].

\section{Fibronectin (FN)}

FN, a component of the ECM, plays an important role in cell adhesion, migration, cell growth and differentiation [141]. The activity of FN is finely tuned by AS that mainly affects three FN regions: the extra domain A (EDA), the extra domain $\mathrm{B}$ (EDB), and the type III connecting sequence (IIICS) [77]. EDA- and EDB-containing isoforms (named oncofetal variants) are abundantly expressed during angiogenic conditions, such as embryogenesis and cancer [77]. In ECs, EDA-FN participates in vascular remodeling and prevents vascular oxidative stress in diabetic conditions [78]. Platelets and macrophages, recruited to the arterial endothelium, induce the expression of both EDA-FN and EDB-FN in response to change in blood flow [35]. In addition, the expression of EDA-FN and EDB-FN is induced in ECs by TGF $\beta$ in a SMAD3- and SMAD4dependent manner, revealing an important interplay between TGF $\beta$ and FN signaling [142]. In ECs, SRSF5 and RBFOX2 mediate the expression of EDA-FN or EDB-FN [31, 143].

\section{Tenascin C (TNC)}

TNC is an extracellular matrix glycoprotein involved in cell adhesion and migration [80]. In glioma patients, TNC overexpression was correlated with vascular mimicry [144], the ability of cancer cells to create vascular channels independently by ECs [145]. Also in astrocytomas, TNC is upregulated specifically in ECs and not in tumor cells and its expression level correlates with angiogenic markers [146]. Several isoforms are generated through AS of exons encoding for fibronectin type IIIlike repeats (FNIII A1-D), in response to growth factors, inflammatory cytokines [80], and mechanical stresses [147]. Splicing isoforms of TNC are divided in "large" and "small", depending on their molecular weight [80]. Whereas the smallest TNC isoform, lacking all AS FNIII exons, promotes cell adhesion, the larger TNC variants, generated by SRSF6 [148], favor cell migration [80]. Importantly, large TNCs are expressed in developing tissues and in pathological tissues that undergo active tissue remodeling, including tumors, pointing to these isoforms as promising targets in anti-cancer approaches [149]. Specific spliced variants or single AS domains have been associated with different kind of tumors [80]. In particular, the large TNC variant [80, 149], containing the FNIII $C$ domain, is mainly expressed around vessels in high grade astrocytoma [81] but it is not present in normal tissues, suggesting that it could represent a therapeutic marker for this kind of tumor.

\section{SLIT guidance ligand 2 (SLIT2)}

SLIT2 is a secreted glycoprotein that binds the Roundabout (Robo) receptors and inhibits EC migration [150]. Depending on the context, it could have either pro- or anti-angiogenic effects [151]. In particular, secretion of SLIT2 by tumor cells generates a signaling gradient that attracts ECs as a fundamental step in the generation of a novel vessel network [152]. Skipping of exon 15 gives rise to the SLIT2- $\Delta$ E15 isoform. While SLIT2 full-length (FL) is expressed and released by tumor cells, SLIT2$\triangle \mathrm{E} 15$ is mainly present in normal tissues. Compared to the FL protein, SLIT2- $\Delta$ E15 reduces EC permeability and enhances tube formation [83].

\section{PECAM1}

PECAM1 is abundantly expressed in ECs, where it localizes at junctions and functions as regulator of vascular permeability [153]. The exons encoding the intracellular domain of PECAM1, which contains docking sites for signaling molecules, are subject to AS [154]. In particular, inclusion or exclusion of exons 12 to 15 leads to isoforms with peculiar roles in EC migration, adhesion, and 
tube formation $[155,156]$. Through removal of the TM domain encoding exon, AS also generates a soluble form of PECAM1, which is able to inhibit adhesive interactions of the membrane-bound PECAM1 form [157].

\section{CD146}

CD146 has been recently proposed as a potential therapeutic target based on its involvement in vascular integrity [158]. Three forms of CD146 have been described and include two transmembrane isoforms, long CD146 (lgCD146) and short CD146 (shCD146), as well as a soluble isoform (sCD146), which circulates in the plasma and derives from metalloprotease-dependent shedding of the previous two proteins [158]. The $\operatorname{lgCD} 146$ and shCD146 isoforms are, respectively, generated by either inclusion or skipping of exon 15 and characterized by different intracellular domains, as well as by diverse cellular localization [158]. In ECs, lgCD146 is present at the junctions, whereas shCD146 localizes at the migrating front [88]. While shCD146 promotes EC proliferation, migration and adhesion, $\operatorname{lgCD} 146$ induces EC tube formation and stabilization [88].

\section{CD44}

CD44, a transmembrane glycoprotein involved in cellcell and cell-matrix interactions, binds hyaluronic acid and other ECM components. A number of CD44 variants are generated through AS of 10 consecutive AS exons ( $v 1$ to 10) encoding for the extracellular juxtamembrane region. The short CD44 protein, lacking all alternative exons, is predominantly expressed in normal tissues, whereas CD44 variants containing exons v5, v6 and $\mathrm{v} 7$, are over-expressed in various cancers and associated to metastasis. In particular, the CD44v6 isoform controls EC migration, sprouting and tube formation through its ability to act as a VEGFR2 co-receptor for VEGF-A [89]. Blockage of co-receptor function of CD44v6 reduces tumor angiogenesis in vivo [89]. Moreover, AS is responsible for the production of a soluble variant of CD44 [159], which competes with membranebound $\mathrm{CD} 44$ protein on EC surface.

\section{Endoglin (ENG)}

ENG, an auxiliary receptor for TGF $\beta$, is mainly expressed on proliferating ECs and upregulated during hypoxia [160]. A short isoform of endoglin (S-endoglin) results from the retention of intron 13 . The canonical long (L-endoglin) and the short S-endoglin proteins differ in their cytoplasmic tails and for their ability to interact with TGF $\beta$ type I receptors ALK1 and ALK5 (Fig. 2b). L-endoglin enhances ALK1 signaling, while Sendoglin promotes ALK5 activation [96, 97]. S-endoglin expression is induced in ECs during senescence and is involved in NO-dependent vascular homeostasis. In senescent ECs, SRSF1 leads to an increased expression of S-endoglin mRNA [161]. More recently, S-endoglinmediated ALK5 signaling has been related to altered pulmonary angiogenesis induced by hyperoxia [98].

\section{Insulin receptor (IR)}

IR (encoded by INSR) has been proposed as tumor EC marker, as it is overexpressed by the vasculature of different cancer types, but not by activated endothelium in physiological conditions [99]. In addition, increased expression of vascular IR is correlated with bad prognosis of cancer patients. AS of INSR gives rise to two different variants: IR-A and IR-B. These two isoforms differ in ligand affinity and cellular downstream signaling [162]. In particular, IR-B is the full-length protein mediating the metabolic function of IR, while the shorter IR-A (lacking exon 11) controls cell proliferation [99]. Since IR-A is overexpressed by the tumor vasculature [99] it could represent a potential target for anti-angiogenic therapies.

\section{Tissue factor (TF)}

TF is a cell surface glycoprotein involved in vessel formation and maturation, as well as in the activation of blood clotting cascade. TF undergoes AS to generate multiple isoforms. In particular, skipping of exon 5 generates the soluble factor asTF (alternatively spliced TF) [163], which lacks any pro-coagulant activity, stimulates tumor growth, angiogenesis, and metastasis [102]. Its expression levels positively correlate with progression in several cancers $[100,101]$.

\section{Cell adhesion molecule L1 (L1CAM)}

L1CAM orchestrates important EC functions, in particular in tumor vasculature [106]. An EC-specific variant of L1CAM (L1- $\triangle \mathrm{TM})$ is generated through skipping of exon 25, which removes the TM domain and generates a soluble protein [106] (Fig. 2b). In ECs, the splicing regulator NOVA2 stimulates L1- $\triangle \mathrm{TM}$ production through direct binding to RNA motifs in exon 25. L1- $\Delta$ TM promotes EC tube formation and sustains neovascularization in vivo in a FGFR1-dependent manner. L1- $\Delta \mathrm{TM}$ is overexpressed in the vasculature of ovarian cancer, where its expression levels correlate with tumor vascularization [106].

\section{SRFs regulating EC functions}

A list of SRFs relevant for vascular development is shown in Supplementary Table 2 (Additional files 1 and 2), based on the Mouse Genome Information (MGI) [164] and the Zebrafish Information Network (ZFIN) [165], which provide information on mouse gene and zebrafish knockouts and their phenotypes. Here, we discuss the current knowledge on SRF critically involved in ECs biology. 


\section{PTBP1}

PTBP1, a broadly expressed SRF, coordinates AS in a variety of processes, including acquisition of cellular morphology, immunity, metabolic control and cell cycle [166]. PTBP1 is expressed at high levels in ECs of different tissues and its expression levels correlate with the inclusion rate of EC-specific exons, particularly in genes involved in cell-cell or cell-matrix adhesion [167].

Quiescent ECs express low levels of PTBP1 [168], while its expression increases in pathological conditions. In pulmonary hypertension, PTBP1 levels increase in arterial vessels, due to partial loss of its negative regulator miR-124 [168]. PTBP1 is also upregulated in blood vessels of glioblastoma multiforme, one of the most aggressive brain cancers [169], and glioma, in which its depletion significantly increases blood-tumor barrier permeability [170]. Consistent with the pro-angiogenic activity of PTBP1, medium conditioned by PTBP1knockdown cells lost the capacity to promote tube formation by HUVECs $[171,172]$.

\section{SRSF1}

SRSF1 is involved in different aspects of RNA metabolism, including splicing, mRNA stability, translation, and miRNA processing [173]. SRSF1 is frequently upregulated in different cancers [24] and a direct target of the oncogenic transcription factor c-Myc [174]. SRSF1 overexpression is sufficient to immortalize rodent fibroblasts and form tumors in mice $[24,175]$, whereas its depletion promotes genomic instability, apoptosis and cell-cycle arrest $[176,177]$. AS regulated by SRSF1 generates protein variants involved in cell migration, epithelial to mesenchymal transition [178], oncogenic activation, loss of tumor suppressor activity $[24,179,180]$ and angiogenesis [181].

SRSF1 controls EC senescence [161] and their response to vascular injury [182]. While it is barely expressed in normal ECs, it increases in cancer ECs [47], often accompanied by upregulation of the proangiogenic VEGF- $\mathrm{A}_{164} \mathrm{a}$ isoform [47] and associated to increased microvessel density [118].

Endothelial SRSF1 expression is induced by the Wilm's tumor suppressor 1 (WT1) transcription factor, whereas its activity is regulated by SRPK, which favors SRSF1 nuclear localization [181]. Knockout of WT1 in tumor endothelium decreased SRPK1 and SRSF1 expression and shifted VEGFA splicing toward the production of the anti-angiogenic $V E G F-A_{120}$ isoform [47].

\section{NOVA2}

Initially considered neuronal-specific [183], NOVA2 is actually expressed by ECs in different blood vessels [184]. For instance, it is abundant in mouse cardiac ECs [185] and preferentially expressed by veins compared to arteries in zebrafish [186]. NOVA2 depletion in ECs impairs the acquisition of cell polarity and the organization of cell-cell junctions, resulting in increased EC migration and permeability [184]. Consistently, nova2 zebrafish mutants present many vascular defects [184]. NOVA2 modulates AS of genes involved in EC cytoskeleton organization and cell-cell adhesion, as well as the transcription factors PPAR- $\gamma$ and E2F Dimerization Partner 2 (Tfdp2) [187]. Very recently NOVA2 was shown to modulate AS of components of Mapk/Erk pathway during lymphatic EC specification [186]. In cancer, such as ovarian and colorectal carcinomas, NOVA2 expression is specifically upregulated in tumor ECs $[106,188]$ and correlates with low survival [106], supporting its potential role as a prognostic marker. A positive correlation between NOVA2 and HIF1- $\alpha$ was observed in colorectal cancer [188], consistent with upregulation of NOVA2 in HUVECs cultured in hypoxic conditions [188].

\section{MBNLS}

MBNLs are tissue-specific RBPs. While MBNL1 is ubiquitously expressed, MBNL2 and MBNL3 are essentially confined to brain and muscle, respectively [189]. MBNL1/2 are upregulated in mature ECs compared to their progenitors [190]. MBNL2 expression has also been reported in HUVECs [191], whereas MBNL1 was found to be expressed and mislocalized in corneal ECs during pathological condition [192]. Several MBNL1-regulated genes are involved in angiogenesis (i.e. VEGFA, ADD3, INF2, SORBS1, FGFR1), EMT, Rho-mediated cytoskeleton dynamics (ARHGEF40, AKAP16) and cell-cell junctions (PPHLN1) [192].

\section{ELAVL1}

ELAVL1, which is involved in a number of physiological processes (i.e. cell proliferation, differentiation, apoptosis) as well as pathologic conditions (i.e. cancer and inflammation) [193], has been mainly characterized for its ability to stabilize mRNA targets. However, it also acts as a SRF [193]. Endothelial-specific knockout of ELAV L1 does not impair either embryonic vascular development or postnatal angiogenesis in adult mice [194]. Nevertheless, these mice are characterized by reduced re-vascularization after hind limb ischemia as well as decreased tumor angiogenesis [194]. In addition, ELAVL knockdown zebrafish embryos show aberrant vascular structures in the intestinal plexus [195]. Consistently, loss of ELAVL1 in cultured ECs impairs their migration and sprouting [194]. Among ELAVL1 splicing targets, Eukaryotic translation initiation factor $4 E$ nuclear import factor 1 (EIF4ENIF1) [194] encodes for the translation initiation factor $4 \mathrm{E}$ transporter $(4 \mathrm{E}-\mathrm{T})$. Depletion of ELAVL1 causes the production of a short isoform (4E$\mathrm{Ts})$ that accelerates degradation of angiogenic regulatory mRNAs (FOS, HIF1- $\alpha$, VEGFA). ELAVL1 is localized in 
Table 2 Therapeutic strategies (Pros \& Cons)

\begin{tabular}{|c|c|c|}
\hline Therapeutic approach & Examples & Pros and cons \\
\hline $\begin{array}{l}\text { Controlling the activity of } \\
\text { splicing factor regulators }\end{array}$ & $\begin{array}{l}\text { - Small molecules targeting SRPK1 (SPHINX, SRPI } \\
\text { N340 and SRPKIN-1) used for VEGFA splicing } \\
\text { correction }[48,198] \text {. }\end{array}$ & $\begin{array}{l}\text { Poor specificity, resulting in AS modification of } \\
\text { multiple genes besides VEGFA. }\end{array}$ \\
\hline $\begin{array}{l}\text { Inhibiting the assembly of } \\
\text { the spliceosome machinery }\end{array}$ & $\begin{array}{l}\text { - Compounds binding to the spliceosome } \\
\text { component SF3b: FR901464 and its methylated } \\
\text { derivative, spliceostatin A [199]. }\end{array}$ & $\begin{array}{l}\text { Poor specificity, affecting AS of multiple genes; } \\
\text { partial understanding of mechanism of action. }\end{array}$ \\
\hline $\begin{array}{l}\text { Interfering with splicing } \\
\text { sites }\end{array}$ & $\begin{array}{l}\text { - Morpholino oligonucleotides targeting the exon } \\
\text { 13/intron } 13 \text { junction of the VEGFR1 pre-mRNA, fa- } \\
\text { voring the production of the anti-angiogenic, sol- } \\
\text { uble form of VEGFR1 [55]. }\end{array}$ & $\begin{array}{l}\text { Possibility to target one single gene; off-target ef- } \\
\text { fects due to either the presence of the targeted } \\
\text { sequence in other portions of the genome or tol- } \\
\text { erance toward mismatches. }\end{array}$ \\
\hline $\begin{array}{l}\text { Blocking pro-angiogenic } \\
\text { isoforms }\end{array}$ & $\begin{array}{l}\text { - Humanized monoclonal antibody [91] or a soluble } \\
\text { peptide [200, 201] against CD44v6. } \\
\text { - Intravenous delivery of autologous T cells, } \\
\text { modified to recognize CD44v6 on the surface of } \\
\text { cancer cells (ClinicalTrials.gov: NCT04427449 [95]). } \\
\text { - Monoclonal antibodies against FGF8b [202]; using } \\
\text { natural inhibitor Pentraxin-3 (PTX3) and its deriva- } \\
\text { tives Ac-ARPCA-NH2 (ARPCA) and 8b-13 [203, 204] } \\
\text { to target FGFs. }\end{array}$ & $\begin{array}{l}\text { High specificity with minimal side effects; } \\
\text { cumbersome and expensive design and } \\
\text { production. }\end{array}$ \\
\hline $\begin{array}{l}\text { Overexpressing anti- } \\
\text { angiogenic isoforms }\end{array}$ & $\begin{array}{l}\text { - Overexpression of sNRP1 to prevent VEGF } \\
\text { signalling [60]. } \\
\text { - Overexpression of either VASH1B or VASH1A [72]. }\end{array}$ & $\begin{array}{l}\text { Delivery requiring either gene therapy or } \\
\text { production of recombinant proteins; no effect on } \\
\text { the level of pro-angiogenic isoforms. }\end{array}$ \\
\hline $\begin{array}{l}\text { Exploiting cancer-specific } \\
\text { isoforms for drug delivery }\end{array}$ & $\begin{array}{l}\text { - Monoclonal antibodies and aptides targeting EDA/ } \\
\text { EDB domains of FN: F8 fused to IL-2 [205, 206]; L19 } \\
\text { fused to either IL-2 or IL-12 [207, 208]; EDB- } \\
\text { targeting aptides conjugated with doxorubicin- } \\
\text { containing liposomes [209, 210]. } \\
\text { - Monoclonal antibodies (F16 fused to IL-2) and } \\
\text { aptamers targeting domains A1-D of TNC [21 1]. }\end{array}$ & $\begin{array}{l}\text { High specificity for cancer cells; cumbersome and } \\
\text { expensive design and production; toxicity related } \\
\text { to the chemotherapeutic agent. }\end{array}$ \\
\hline
\end{tabular}

the cytoplasm of tumor ECs, in which it controls survival, migration and tube formation [196].

\section{RBFOX2}

RBFOX proteins (RBFOX1, RBFOX2 and RBFOX3) control AS in brain [197]. However, RBFOX2 is also expressed by the arterial ECs, in which it mediates the cellular response to low blood flow [31]. A number of EC-specific RBFOX2 splicing targets encode for ECM components or factors involved in cell adhesion, cell cycle, cytoskeletal remodeling and immune response [31]. Similar to NOVA2 [184, 187], RBFOX2 also regulates the abundance of mRNAs transcribed from genes that belong to the same GO categories [31], suggesting that similar biological processes could be modulated by RBFOX2 in ECs through both transcriptional and posttranscriptional mechanisms.

\section{Therapeutic strategies exploiting AS of angiogenic factors in cancer}

Since multiple alterations in AS appear to be specific for cancer angiogenesis, the obvious implication is whether we can manipulate and therapeutically block this process, hence disfavoring tumor growth.

Multiple molecular tools have been exploited to target aberrant AS variants (Table 2). The most common ones are monoclonal antibodies, small molecules, and various types of oligonucleotides. These include: i) small interfering RNAs (siRNAs) targeting one particular AS isoform, ii) modified single stranded RNA decoy oligonucleotides inhibiting the biological activity of splicing regulators, and iii) splicing-switching oligos, $\sim 20$ base long modified oligonucleotides binding specific splicing regulatory sites.

These tools have been variably used to interfere with cancer-specific AS. The following paragraphs describe the strategies that have been so far considered most promising for human application. An overview of the existing approaches, together with their major advantages and disadvantages, is provided in Table 2.

\section{Drugs targeting splicing factor regulators}

SRPK1 activity has been associated to increased tumor cell proliferation, migration and angiogenesis in different cancers $[212,213]$. The evidence that SRPK1 inhibition switches the pro-angiogenic VEGF- $\mathrm{A}_{165} \mathrm{a}$ into the antiangiogenic VEGF- $\mathrm{A}_{165} \mathrm{~b}$ isoform [181] leaded to the generation of a plethora of small molecules targeting SRPK1, such as SPHINX and its derivatives, SRPIN340 and SRPKIN-1, which are the most effective ones in correcting VEGFA splicing. These molecules are able to efficiently block angiogenesis in murine models of both macular degeneration and cancer $[48,198]$. 


\section{Inhibitors of spliceosome assembly}

One of the first approaches able to interfere with AS in cancer angiogenesis exploits compounds inhibiting the spliceosome assembly. A paradigmatic example is the natural product FR901464 and its methylated derivative, spliceostatin A, which binds to the spliceosome component SF3b [199]. In a chicken chorioallantoic membrane (CAM) assay, spliceostatin A reduced the expression of $38 \%$ of total genes (including VEGFA) and inhibited cancer cell-derived angiogenesis [49].

\section{Interference with splicing sites}

Chemically modified antisense oligonucleotides, targeting sequences recognized by the spliceosome or splicing factors, can be exploited to re-direct splice site selection and to correct AS decisions. While their use is widely exploited to interfere with a variety of molecules controlling cancer cell survival and proliferation [214], a few studies have started investigating their therapeutic potential in modulating cancer angiogenesis. Interestingly, morpholino oligonucleotides targeting the exon 13/intron 13 junction of the VEGFR1 pre-mRNA, have been used to favor the production of the anti-angiogenic, soluble form of the receptor (sVEGFR1). The repeated injection of these oligonucleotides in human breast cancer tumors, implanted subcutaneously into nude mice, inhibited cancer vascularization and progression [55].

\section{Blocking pro-angiogenic splicing isoforms}

An obvious approach to modulate AS in cancer angiogenesis is the selective inhibition of pro-angiogenic isoforms. This can be efficiently achieved using peptides, monoclonal antibodies or chimeric antigen receptor (CAR)-T cells. Numerous experimental and clinical studies are targeting pro-angiogenic isoforms of CD44, which are expressed by multiple cancer cell types. Current strategies mainly target CD44v6, using either a humanized monoclonal antibody [91] or a soluble peptide $[200,201,215]$ that blocks exon v6-encoded domain. A clinical trial is currently ongoing to evaluate the efficacy of the intravenous delivery of autologous T cells, genetically modified with lentiviral CAR vector, to recognize CD44v6 on the surface of cancer cells (ClinicalTrials.gov: NCT04427449 [95]). Additional strategies, which have not been tested in human cancer, target FGF ligands, with particular attention to some FGF isoforms that are preferentially expressed by specific tumor types. For example, the activity of FGF8b, overexpressed by hormone-dependent tumors, can be blocked using either monoclonal antibodies [202] or its natural inhibitor Pentraxin-3 (PTX3) and its derivatives Ac-ARPCA-NH2 (ARPCA) and 8b-13. While these peptides also block FGF2, they show higher affinity for FGF8b. In particular, FGF8b inhibition by ARPCA decreased HUVECs migration and sprouting, and resulted in reduced proliferation and vascularization of androgen-dependent mouse mammary tumors implanted into the flank of nude mice [203, 204].

\section{Overexpression of (naturally existing) anti-angiogenic splicing isoforms}

Anti-angiogenic isoforms can be overexpressed to block tumor vascularization. Starting from the evidence that soluble neuropilins prevent VEGF signalling, sNRP1 has been overexpressed by adenoviral vectors, resulting in reduced angiogenesis and delayed disease progression in mouse models of myeloid sarcoma and acute myeloid leukemia [60].

An additional example in this category is the overexpression of either VASH1B, which induced tumor necrosis in murine model of human breast carcinoma, or VASH1A, which resulted in tumor vessel normalization and improved perfusion. The simultaneous overexpression of both isoforms was even more effective in inhibiting cancer growth and normalizing its vasculature [72].

\section{Targeting cancer-specific AS isoforms for drug delivery}

The evidence that the tumor vasculature tends to selectively express specific AS isoforms paved the way to target them to facilitate drug delivery to the neoplastic mass.

Several compounds and peptides have been developed to target either the EDA or the EDB domains of fibronectin [79]. For instance, the F8 monoclonal antibody, targeting EDA, has been fused to IL-2 to stimulate the immune system specifically at the level of the tumor. This strategy successfully inhibited the tumor growth in multiple models of murine xenografts, particularly when associated to either chemotherapeutic drugs or antiangiogenic molecules [205, 206]. A similar strategy has been used even more widely to target EDB. The human EDB domain specific antibody, L19 was particularly effective in both pre-clinical and clinical studies, when fused to either IL-2 or IL-12 [207, 208].

In addition to antibodies, peptides have been generated to target fibronectin for tumor drug delivery. Aptides are short high-affinity peptides consisting of two EDB-targeting moieties linked by a tryptophan zipper region. When conjugated with doxorubicin-containing liposomes, they promoted drug delivery to glioma tumor allografts in mice, determining a 55\% decrease in tumor size compared to $20 \%$ decrease induced by free doxorubicin $[209,210]$.

Finally, the preferential expression of long TNC isoforms in cancer can also be targeted for drug delivery. Antibodies targeting the AS domains A1 to D (variably present in the longer isoforms of TNC) [216] have been evaluated in preclinical studies and a few have reached the clinical arena. The most advanced results are available for one of these antibodies (F16) fused to IL2 for 
the therapy of different metastatic cancers [211]. The same TNC domains can be targeted using aptamers, which can be chemically synthetized and, being small molecules, show superior biodistribution compared to monoclonal antibodies. The specificity of these aptamers (i.e. TTA1 and GBI-10) has been proven in vitro, but their in vivo application has never been tested yet.

\section{Conclusions}

Based on its pervasive use and its high molecular versatility, AS has a central role in gene expression regulation in human cells. However, unlike the well-characterized pathways controlling angiogenesis at transcriptional level, our knowledge of how AS impacts on EC functions are still limited. Thus, future works are needed to i) characterize the functional role of most AS variants in ECs; ii) better understand how cis-acting motifs and their cognate RBPs act together to modulate AS of specific genes, and iii) comprehend how the splicing is integrated with other cellular processes (such as transcription, epigenetic modifications and signaling pathways).

In cancer vessels tumor ECs express several atypical splicing isoforms not expressed (or expressed at low levels) in normal ECs, which could represent putative targets for anti-angiogenic therapy. Indeed, aberrant AS in tumor vasculature is emerging as a promising concept paving the way to anti-cancer therapeutic strategies. A deeper understanding of the AS errors occurring during cancer development and progression could allow formulating more specific and effective therapies. To what extent AS is specifically altered in different tumor types remains an outstanding question. The answer will possibly set AS in the field of theranostics, a new medical area combining targeted therapies with specifically targeted diagnostic tests. Since AS can be interrogated by common and relatively inexpensive techniques (i.e. RTPCR), it could be rapidly analyzed at the time of tumor resection to select the most effective combination of drugs for each patient. Among the different strategies considered so far, monoclonal antibodies represent perhaps the most promising approach, as they are already in clinical practice for numerous disorders, including cancer, and platforms for their production, albeit expensive, could be easily adapted to new use. The possibility to fuse them to immune regulators, triggering patient's immune response directly at the tumor site, further extends their therapeutic potential. Finally, the emerging evidence of the existence of cancer-specific AS isoforms will surely offer new opportunities for combination therapies, as standard chemotherapy can be potentiated by targeting these AS isoforms to induce vessel normalization, thus improving perfusion and drug delivery.

Understanding the contribution of AS regulation in tumor angiogenesis goes beyond the possibility of directly exploiting it as a source of new therapeutic targets. Indeed, identifying AS variants in cancer vasculature - as well as studying their functions and the molecular mechanisms underlying their production would deepen our comprehension of the angiogenic process and allow to discover novel pathways relevant for cancer progression.

\section{Supplementary Information}

The online version contains supplementary material available at https://doi. org/10.1186/s13046-020-01753-1.

Additional file 1: Supplementary Table 1. Additional AS isoforms (or events) relevant for angiogenesis and EC biology. Supplementary Table 2. RBPs whose deficiency results in aberrant vascular phenotypes in mice (MGl database) or Zebrafish (Danio rerio) (ZFIN database).

Additional file 2. Additional References.

\section{Abbreviations}

AS: Alternative Splicing; EC(s): Endothelial Cell(s); Pre-mRNA: Precursor messenger RNA; RBPs: RNA Binding Proteins; SR: Serine-Arginine rich; hnRNPs: Heterogeneous Nuclear Ribonucleoproteins; SRFs: Splicing Regulatory Factors; RNA pol II: RNA Polymerase II; RNA-seq: RNA Sequencing; ECM: Extracellular Matrix; HUVECs: Human Umbilical Vein Endothelial Cells; TM: Transmembrane Domain; FL: Full Lenght; CAM: Chorioallantoic Membrane; CAR: Chimeric Antigen Receptor; PTX3: Pentraxin 3; RTPCR: Reverse Transcription-Polymerase Chain Reaction; ISS: Intronic Splicing Silencer; ESS: Exonic Splicing Silencer; ESE: Exonic Splicing Enhancer; ISE: Intronic Splicing Enhancer; BP: Branch Point; SSOs: Splice-Switching Oligonucleotides

\section{Acknowledgements}

N/A.

Authors' contributions

$A D M, E B, D P, A C$ and NV were major contributors in writing this review and they wrote the initial draft of the manuscript, whereas SZ and GC revised, expanded and suggested changes to the original version of the manuscript. All authors have seen and approved the final manuscript.

\section{Funding}

This work was supported by grant from the Associazione Italiana per la Ricerca sul Cancro (AIRC) IG 2018 Id.21966 to CG and IG 2016 Id.19032 to SZ. DP is supported by a AIRC fellowship for Italy. We thank the "Fondazione Adriano Buzzati-Traverso" for the support.

\section{Availability of data and materials}

N/A.

\section{Ethics approval and consent to participate}

N/A.

\section{Consent for publication}

N/A.

\section{Competing interests}

CG is a consultant for Gene Tools. All other authors declare that they have no competing interest. Funding bodies had no role in the design of the study and collection, analysis and interpretation of data, and in writing the manuscript.

\section{Author details}

'Istituto di Genetica Molecolare, "Luigi Luca Cavalli-Sforza", Consiglio Nazionale delle Ricerche, via Abbiategrasso 207, 27100 Pavia, Italy.

${ }^{2}$ Cardiovascular Biology Laboratory, International Centre for Genetic

Engineering and Biotechnology (ICGEB), 34149 Trieste, Italy. ${ }^{3}$ Department of 
Medical, Surgical and Health Sciences, University of Trieste, 34149 Trieste, Italy.

\section{Received: 18 August 2020 Accepted: 26 October 2020} Published online: 07 December 2020

\section{References}

1. Folkman MJ, Long DM, Becker FF. Tumor growth in organ culture. Surg Forum. 1962;13:81-3.

2. Greenblatt M, Philippe SK. Tumor angiogenesis: Transfilter diffusion studies in the hamster by the transparent chamber technique. J Natl Cancer Inst. 1968:41:111-24.

3. Ehrmann RL, Knoth M. Choriocarcinoma: Transfilter stimulation of vasoproliferation in the hamster cheek pouch—studied by light and electron microscopy. J Natl Cancer Inst. 1968;41:1329-41.

4. Folkman J, Merler E, Abernathy C, Williams G. Isolation of a tumor factor responsible for angiogenesis. J Exp Med. 1971;133:275-88.

5. Folkman J. Tumor angiogenesis: therapeutic implications. N Engl J Med. 1971:285:1182-6.

6. Gimbrone MA, Leapman SB, Cotran RS, Folkman J. Tumor dormancy in vivo by prevention of neovascularization. J Exp Med. 1972;136:261-76.

7. Ferrara N. VEGF and the quest for tumour angiogenesis factors. Nat Rev Cancer. 2002;2:795-803.

8. Will CL, Lührmann R. Spliceosome structure and function. Cold Spring Harb Perspect Biol. 2011;3:a003707.

9. Kelemen O, Convertini P, Zhang Z, Wen Y, Shen M, Falaleeva M, et al. Function of alternative splicing. Gene. 2013;514:1-30.

10. Pan $Q$, Shai $O$, Lee $L$, Frey BJ, Blencowe BJ. Deep surveying of alternative splicing complexity in the human transcriptome by high-throughput sequencing. Nat Genet. 2008;40:1413-5.

11. Wang ET, Sandberg R, Luo S, Khrebtukova I, Zhang L, Mayr C, et al. Alternative isoform regulation in human tissue transcriptomes. Nature. 2008; 456:470-6.

12. Gerstein MB, Lu ZJ, Van Nostrand EL, Cheng C, Arshinoff BI, Liu T, et al. Integrative analysis of the Caenorhabditis elegans genome by the modENCODE project. Science. 2010;330:1775-87.

13. Graveley BR, Brooks AN, Carlson JW, Duff MO, Landolin JM, Yang L, et al. The developmental transcriptome of Drosophila melanogaster. Nature. 2011;471:473-9.

14. Ramani AK, Calarco JA, Pan Q, Mavandadi S, Wang Y, Nelson AC, et al. Genome-wide analysis of alternative splicing in Caenorhabditis elegans. Genome Res. 2011;21:342-8.

15. Baralle FE, Giudice J. Alternative splicing as a regulator of development and tissue identity. Nat Rev Mol Cell Biol. 2017;18:437-51.

16. Dvinge $H$. Regulation of alternative mRNA splicing: old players and new perspectives. FEBS Lett. 2018;592:2987-3006.

17. Manley JL, Krainer AR. A rational nomenclature for serine/arginine-rich protein splicing factors (SR proteins). Genes Dev. 2010;24:1073-4.

18. Han SP, Tang YH, Smith R. Functional diversity of the hnRNPs: past, present and perspectives. Biochem J. 2010;430:379-92.

19. Buratti $E$, Baralle FE. Influence of RNA secondary structure on the pre-mRNA splicing process. Mol Cell Biol. 2004;24:10505-14.

20. Luco RF, Allo M, Schor IE, Kornblihtt AR, Misteli T. Epigenetics in alternative pre-mRNA splicing. Cell. 2011;144:16-26.

21. Kornblihtt AR. Coupling transcription and alternative splicing. Adv Exp Med Biol. 2007;623:175-89.

22. Oltean S, Bates DO. Hallmarks of alternative splicing in cancer. Oncogene. 2014;33:5311-8

23. Biamonti G, Catillo M, Pignataro D, Montecucco A, Ghigna C. The alternative splicing side of cancer. Semin Cell Dev. 2014;32:30-6.

24. Karni R, De Stanchina E, Lowe SW, Sinha R, Mu D, Krainer AR. The gene encoding the splicing factor SF2/ASF is a proto-oncogene. Nat Struct Mol Biol. 2007:14:185-93.

25. Golan-Gerstl R, Cohen M, Shilo A, Suh SS, Bakàcs A, Coppola L, et al. Splicing factor hnRNP A2/B1 regulates tumor suppressor gene splicing and is an oncogenic driver in glioblastoma. Cancer Res. 2011;71:4464-72.

26. Wang Y, Chen D, Qian H, Tsai YS, Shao S, Liu Q, et al. The splicing factor RBM4 controls apoptosis, proliferation, and migration to suppress tumor progression. Cancer Cell. 2014;26:374-89.
27. Zong FY, Fu X, Wei WJ, Luo YG, Heiner M, Cao LJ, et al. The RNA-binding protein QKI suppresses cancer-associated aberrant splicing. PLoS Genet. 2014;10:e1004289.

28. Bonomi S, Gallo S, Catillo M, Pignataro D, Biamonti G, Ghigna C. Oncogenic alternative splicing switches: role in cancer progression and prospects for therapy. Int J Cell Biol. 2013;2013:962038.

29. Zhu J, Chen Z, Yong L. Systematic profiling of alternative splicing signature reveals prognostic predictor for ovarian cancer. Gynecol Oncol. 2018;148:368-74.

30. Kahles A, Lehmann KV, Toussaint NC, Hüser M, Stark SG, Sachsenberg T, et al. Comprehensive analysis of alternative splicing across tumors from 8,705 patients. Cancer Cell. 2018;34:211-224.e6.

31. Murphy PA, Butty VL, Boutz PL, Begum S, Kimble AL, Sharp PA, et al. Alternative RNA splicing in the endothelium mediated in part by Rbfox2 regulates the arterial response to low flow. Elife. 2018;7:e29494.

32. Gorospe M, Abdelmohsen K. MicroRegulators come of age in senescence. Trends Genet. 2011;27:233-41.

33. Cunningham KS, Gotlieb Al. The role of shear stress in the pathogenesis of atherosclerosis. Lab Investig. 2005;85:9-23.

34. Buchanan CF, Verbridge SS, Vlachos PP, Rylander MN. Flow shear stress regulates endothelial barrier function and expression of angiogenic factors in a 3D microfluidic tumor vascular model. Cell Adhes Migr. 2014;8:517-24.

35. Murphy PA, Hynes RO. Alternative splicing of endothelial fibronectin is induced by disturbed hemodynamics and protects against hemorrhage of the vessel wall. Arterioscler Thromb Vasc Biol. 2014;34:2042-50.

36. Ning W, Chu TJ, Li CJ, Choi AMK, Peters DG. Genome-wide analysis of the endothelial transcriptome under short-term chronic hypoxia. Physiol Genomics. 2004;18:70-8.

37. Carmeliet P, Jain RK. Molecular mechanisms and clinical applications of angiogenesis. Nature. 2011;473:298-307.

38. Petrova V, Annicchiarico-Petruzzelli M, Melino G, Amelio I. The hypoxic tumour microenvironment. Oncogenesis. 2018;7:10.

39. Manalo DJ, Rowan A, Lavoie T, Natarajan L, Kelly BD, Ye SQ, et al. Transcriptional regulation of vascular endothelial cell responses to hypoxia by HIF-1. Blood. 2005;105:659-69.

40. Scheurer SB, Rybak JN, Rösli C, Neri D, Elia G. Modulation of gene expression by hypoxia in human umbilical cord vein endothelial cells: a transcriptomic and proteomic study. Proteomics. 2004;4:1737-60.

41. Hang X, Li P, Li Z, Qu W, Yu Y, Li H, et al. Transcription and splicing regulation in human umbilical vein endothelial cells under hypoxic stress conditions by exon array. BMC Genomics. 2009;10:126.

42. Weigand JE, Boeckel J-N, Gellert P, Dimmeler S. Hypoxia-induced alternative splicing in endothelial cells. PLoS One. 2012;7:e42697.

43. Xing Y, Kapur K, Wong WH. Probe selection and expression index computation of Affymetrix exon arrays. PLoS One. 2006;1:e88.

44. Han J, Li J, Ho JC, Chia GS, Kato H, Jha S, et al. Hypoxia is a key driver of alternative splicing in human breast Cancer cells. Sci Rep. 2017;7:4108.

45. Brady LK, Wang H, Radens CM, Bi Y, Radovich M, Maity A, et al. Transcriptome analysis of hypoxic cancer cells uncovers intron retention in EIF2B5 as a mechanism to inhibit translation. PLoS Biol. 2017;15:e2002623.

46. Biselli-Chicote PM, Oliveira ARCP, Pavarino EC, Goloni-Bertollo EM. VEGF gene alternative splicing: pro- and anti-angiogenic isoforms in cancer. J Cancer Res Clin Oncol. 2012;138:363-70.

47. Wagner KD, El Maï M, Ladomery M, Belali T, Leccia N, Michiels JF, et al. Altered VEGF splicing isoform balance in tumor endothelium involves activation of splicing factors Srpk1 and Srsf1 by the Wilms' tumor suppressor Wt1. Cells. 2019;8:41.

48. Hatcher JM, Wu G, Zeng C, Zhu J, Meng F, Patel S, et al. SRPKIN-1: a covalent SRPK1/2 inhibitor that potently converts VEGF from proangiogenic to anti-angiogenic isoform. Cell Chem Biol. 2018;25:460-470.e6.

49. Furumai R, Uchida $\mathrm{K}$, Komi $\mathrm{Y}$, Yoneyama $\mathrm{M}$, Ishigami $\mathrm{K}$, Watanabe $\mathrm{H}$, et al. Spliceostatin a blocks angiogenesis by inhibiting global gene expression including VEGF. Cancer Sci. 2010;101:2483-9.

50. Yamano T, Kubo S, Yano A, Kominato T, Tanaka S, Ikeda M, et al. Splicing modulator FR901464 is a potential agent for colorectal cancer in combination therapy. Oncotarget. 2019;10:352-67.

51. Failla CM, Carbo M, Morea V. Positive and negative regulation of angiogenesis by soluble vascular endothelial growth factor receptor-1. Int J Mol Sci. 2018;19:1306.

52. Abou Faycal C, Brambilla E, Agorreta J, Lepeltier N, Jacquet T, Lemaître $N$, et al. The sVEGFR1-i13 splice variant regulates a $\beta 1$ integrin/NEGFR autocrine 
loop involved in the progression and the response to anti-angiogenic therapies of squamous cell lung carcinoma. Br J Cancer. 2018;118:1596-608.

53. Bando H, Weich HA, Brokelmann M, Horiguchi S, Funata N, Ogawa T, et al. Association between intratumoral free and total VEGF, soluble VEGFR-1, VEGFR-2 and prognosis in breast cancer. Br J Cancer. 2005;92:553-61.

54. Yamaguchi T, Bando H, Mori T, Takahashi K, Matsumoto H, Yasutome M, et al. Overexpression of soluble vascular endothelial growth factor receptor 1 in colorectal cancer: association with progression and prognosis. Cancer Sci. 2007:98:405-10.

55. Owen LA, Uehara H, Cahoon J, Huang W, Simonis J, Ambati BK. Morpholino-mediated increase in soluble Flt-1 expression results in decreased ocular and tumor neovascularization. PLoS One. 2012;7:e33576.

56. Becker J, Pavlakovic H, Ludewig F, Wilting F, Weich HA, Albuquerque R, et al. Neuroblastoma progression correlates with downregulation of the lymphangiogenesis inhibitor sVEGFR-2. Clin Cancer Res. 2010;16:1431-41.

57. Gagnon ML, Bielenberg DR, Gechtman Z, Miao HQ, Takashima S, Soker S, et al. Identification of a natural soluble neuropilin-1 that binds vascular endothelial growth factor: in vivo expression and antitumor activity. Proc Natl Acad Sci U S A. 2000;97:2573-8.

58. Rossignol M, Gagnon ML, Klagsbrun M. Genomic organization of human neuropilin-1 and neuropilin-2 genes: identification and distribution of splice variants and soluble isoforms. Genomics. 2000;70:211-22.

59. Cackowski FC, Xu L, Hu B, Cheng SY. Identification of two novel alternatively spliced Neuropilin-1 isoforms. Genomics. 2004;84:82-94.

60. Schuch G, Machluf M, Bartsch G, Nomi M, Richard H, Atala A, et al. In vivo administration of vascular endothelial growth factor (VEGF) and its antagonist, soluble neuropilin-1, predicts a role of VEGF in the progression of acute myeloid leukemia in vivo. Blood. 2002;100:4622-8.

61. Hendricks C, Dubail J, Brohée L, Delforge Y, Colige A, Deroanne C. A novel physiological glycosaminoglycan-deficient splice variant of neuropilin-1 is anti-tumorigenic in vitro and in vivo. PLoS One. 2016;11:e0165153.

62. Huang $X$, Ye Q, Chen M, Li A, Mi W, Fang Y, et al. N-glycosylation-defective splice variants of neuropilin-1 promote metastasis by activating endosomal signals. Nat Commun. 2019;10:3708.

63. Parker MW, Linkugel AD, Goel HL, Wu T, Mercurio AM, Vander Kooi CW. Structural basis for VEGF-C binding to neuropilin-2 and sequestration by a soluble splice form. Structure. 2015;23:677-87.

64. Turner N, Grose R. Fibroblast growth factor signalling: from development to cancer. Nat Rev Cancer. 2010;10:116-29.

65. Narita K, Fujii T, Ishiwata T, Yamamoto T, Kawamoto Y, Kawahara K, et al. Keratinocyte growth factor induces vascular endothelial growth factor - a expression in colorectal cancer cells. Int J Oncol. 2009;34:355-60.

66. Cho K, Matsuda Y, Ueda J, Uchida E, Naito Z, Ishiwata T. Keratinocyte growth factor induces matrix metalloproteinase-9 expression and correlates with venous invasion in pancreatic cancer. Int J Oncol. 2012;40:1040-8.

67. Bai A, Meetze K, Vo NY, Kollipara S, Mazsa EK, Winston WM, et al. GP369, an FGFR2-IIIb-specific antibody, exhibits potent antitumor activity against human cancers driven by activated FGFR2 signaling. Cancer Res. 2010;70:7630-9.

68. Antoine M, Wirz W, Tag CG, Mavituna M, Emans N, Korff T, et al. Expression pattern of fibroblast growth factors (FGFs), their receptors and antagonists in primary endothelial cells and vascular smooth muscle cells. Growth Factors. 2005;23:87-95.

69. Bowler E, Oltean S. Alternative splicing in angiogenesis. Int J Mol Sci. 2019; 20:2067.

70. Cha JY, Maddileti S, Mitin N, Harden TK, Der CJ. Aberrant receptor internalization and enhanced FRS2-dependent signaling contribute to the transforming activity of the fibroblast growth factor receptor 2 IIIb C3 isoform. J Biol Chem. 2009;284:6227-40.

71. Burgar HR, Burns HD, Elsden JL, Lalioti MD, Heath JK. Association of the signaling adaptor FRS2 with fibroblast growth factor receptor 1 (FGFR1) is mediated by alternative splicing of the juxtamembrane domain. J Biol Chem. 2002:277:4018-23.

72. Horie S, Suzuki Y, Kobayashi M, Kadonosono T, Kondoh S, Kodama T, et al. Distinctive role of vasohibin-1A and its splicing variant vasohibin-1B in tumor angiogenesis. Cancer Gene Ther. 2016;23:133-41.

73. Sato $\mathrm{Y}$, Sonoda $\mathrm{H}$. The vasohibin family: a negative regulatory system of angiogenesis genetically programmed in endothelial cells. Arterioscler Thromb Vasc Biol. 2007;27:37-41.

74. Haung YQ, Yang X, Brown J, Ramakrishnan A, Torok-Storb B, Kabos P, et al. Identification of a family of alternatively spliced mRNA species of angiopoietin-1. Blood. 2000;95:1993-9.
75. Kim I, Kim JH, Ryu YS, Jung SH, Nah JJ, Koh GY. Characterization and expression of a novel alternatively spliced human angiopoietin-2. J Biol Chem. 2000;275:18550-6.

76. Mezquita J, Mezquita B, Pau M, Mezquita C. Characterization of a novel form of angiopoietin-2 (Ang-2B) and expression of VEGF and angiopoietin-2 during chicken testicular development and regression. Biochem Biophys Res Commun. 1999;260:492-8.

77. White ES, Baralle FE, Muro AF. New insights into form and function of fibronectin splice variants. J Pathol. 2008:216:1-14.

78. Gortan Cappellari G, Barazzoni R, Cattin L, Muro AF, Zanetti M. Lack of fibronectin extra domain a alternative splicing exacerbates endothelial dysfunction in diabetes. Sci Rep. 2016;6:37965.

79. Kumra H, Reinhardt DP. Fibronectin-targeted drug delivery in cancer. Adv Drug Deliv Rev. 2016;97:101-10.

80. Giblin SP, Midwood KS. Tenascin-C: form versus function. Cell Adhes. 2015;9: 48-82.

81. Carnemolla B, Castellani P, Ponassi M, Borsi L, Urbini S, Nicolo G, et al. Identification of a glioblastoma-associated Tenascin-C isoform by a high affinity recombinant antibody. Am J Pathol. 1999;154:1345-52.

82. Hicke BJ, Marion C, Chang YF, Gould T, Lynott CK, Parma D, et al. Tenascin-C Aptamers are generated using tumor cells and purified protein. J Biol Chem. 2001;276:48644-54.

83. Yang YC, Chen PN, Wang SY, Liao CY, Lin YY, Sun SR, et al. The differential roles of Slit2-exon 15 splicing variants in angiogenesis and HUVEC permeability. Angiogenesis. 2015;18:301-12.

84. Wang Y, Su X, Sorenson CM, Sheibani N. Tissue-specific distributions of alternatively spliced human PECAM-1 isoforms. Am J Physiol Heart Circ Physiol. 2003;284:H1008-17.

85. Wang Y, Repyak K, Sheibani N. Expression pattern of alternatively spliced PECAM-1 isoforms in retinal vasculature. Mol Vis. 2004;10:103-11.

86. Park S, Sorenson CM, Sheibani N. PECAM-1 isoforms, eNOS and endoglin axis in regulation of angiogenesis. Clin Sci. 2015;129:217-34.

87. Goldberger A, Middleton KA, Oliver JA, Paddock C, Yan HC, DeLisser HM, et al. Biosynthesis and processing of the cell adhesion molecule PECAM-1 includes production of a soluble form. J Biol Chem. 1994;269:17183-91.

88. Kebir A, Harhouri K, Guillet B, Liu JW, Foucault-Bertaud A, Lamy E, et al. CD146 short isoform increases the proangiogenic potential of endothelial progenitor cells in vitro and in vivo. Circ Res. 2010;107:66-75.

89. Tremmel M, Matzke A, Albrecht I, Laib AM, Olaku V, Ballmer-Hofer K, et al. A CD44v6 peptide reveals a role of CD44 in VEGFR-2 signaling and angiogenesis. Blood. 2009;114:5236-44.

90. Li L, Schmitt M, Matzke-Ogi A, Wadhwani P, Orian-Rousseau V, Levkin PA. CD44v6-peptide functionalized nanoparticles selectively bind to metastatic cancer cells. Adv Sci (Weinh). 2016;4:1600202.

91. Menke-van der Houven van Oordt CW, Gomez-Roca C, van Herpen C, Coveler AL, Mahalingam D, HMW V, et al. First-in-human phase I clinical trial of RG7356, an anti-CD44 humanized antibody, in patients with advanced, CD44-expressing solid tumors. Oncotarget. 2016;7:80046-58.

92. Misra S, Hascall VC, De Giovanni C, Markwald RR, Ghatak S. Delivery of CD44 shRNA/nanoparticles within cancer cells. Perturbation of hyaluronan/CD44v6 interactions and reduction in adenoma growth in Apc min/+mice. J Biol Chem. 2009;284:12432-46.

93. Hu S, Cao M, He Y, Zhang G, Liu Y, Du Y, et al. CD44v6 targeted by miR193b-5p in the coding region modulates the migration and invasion of breast cancer cells. J Cancer. 2020;11:260-71.

94. Reedeer JA, Gotley DC, Walsh MD, Fawcett J, Antalis TM. Expression of antisense CD44 variant 6 inhibits colorectal tumor metastasis and tumor growth in a wound environment. Cancer Res. 1998;58:3719-26.

95. ClinicalTrials.gov. Bethesda (MD): National Library of Medicine, (US). 2000. 4SCAR-CD44v6 T Cell Therapy Targeting Cancer. Identifier NCT04427449. 2020. Available from: https://clinicaltrials.gov/ct2/show/NCT04427449.

96. Velasco S, Alvarez-Muñoz P, Pericacho M, Ten Dijke P, Bernabéu C, LópezNovoa JM, et al. L- and S-endoglin differentially modulate TGFbeta1 signaling mediated by ALK1 and ALK5 in L6E9 myoblasts. J Cell Sci. 2008; 121:913-9.

97. Blanco FJ, Grande MT, Langa C, Oujo B, Velasco S, Rodriguez-Barbero A, et al. S-endoglin expression is induced in senescent endothelial cells and contributes to vascular pathology. Circ Res. 2008;103:1383-92.

98. Lee Y, Lee J, Nam SK, Hoon JY. S-endoglin expression is induced in hyperoxia and contributes to altered pulmonary angiogenesis in bronchopulmonary dysplasia development. Sci Rep. 2020;10:3043. 
99. Nowak-Sliwinska P, van Beijnum JR, Huijbers EJM, Gasull PC, Mans L, Bex A, et al. Oncofoetal insulin receptor isoform a marks the tumour endothelium; an underestimated pathway during tumour angiogenesis and angiostatic treatment. Br J Cancer. 2019;120:218-28.

100. Ramchandani D, Unruh D, Lewis CS, Bogdanov VY, Weber GF. Activation of carbonic anhydrase IX by alternatively spliced tissue factor under late-stage tumor conditions. Lab Investig. 2016;96:1234-45.

101. Unruh D, Turner K, Srinivasan R, Kocatürk B, Qi X, Chu Z, et al. Alternatively spliced tissue factor contributes to tumor spread and activation of coagulation in pancreatic ductal adenocarcinoma. Int J Cancer. 2014;134:9-20.

102. Pan L, Yu Y, Yu M, Yao S, Mu Q, Luo G, et al. Expression of fiTF and asTF splice variants in various cell strains and tissues. Mol Med Rep. 2019;19:2077-86.

103. Breij ECW, De Goeij BECG, Verploegen S, Schuurhuis DH, Amirkhosravi A, Francis J, et al. An antibody-drug conjugate that targets tissue factor exhibits potent therapeutic activity against a broad range of solid tumors. Cancer Res. 2014;74:1214-26.

104. Eisenreich A, Bolbrinker J, Leppert U. Tissue factor: a conventional or alternative target in cancer therapy. Clin Chem. 2016;62:563-70.

105. Versteeg HH, Schaffner F, Kerver M, Petersen HH, Ahamed J, FeldingHabermann B, et al. Inhibition of tissue factor signaling suppresses tumor growth. Blood. 2008;111:190-9.

106. Angiolini F, Belloni E, Giordano M, Campioni M, Forneris F, Paronetto MP, et al. A novel L1CAM isoform with angiogenic activity generated by NOVA2-mediated alternative splicing. Elife. 2019;8:e44305

107. Magrini E, Villa A, Angiolini F, Doni A, Mazzarol G, Rudini N, et al. Endothelial deficiency of $L 1$ reduces tumor angiogenesis and promotes vessel normalization. J Clin Invest. 2014;124:4335-50.

108. Carmeliet P. VEGF gene therapy: stimulating angiogenesis or angiomagenesis? Nat Med Nat Med. 2000;6:1102-3.

109. Berse B, Brown LF, Van de Water L, Dvorak HF, Senger DR. Vascular permeability factor (vascular endothelial growth factor) gene is expressed differentially in normal tissues, macrophages, and tumors. Mol Biol Cell. 1992;3:211-20

110. Peach CJ, Mignone WW, Arruda MA, Alcobia DC, Hill SJ, Kilpatrick LE, et al. Molecular pharmacology of VEGF-A isoforms: binding and signalling at VEGFR2. Int J Mol Sci. 2018:19:1264

111. Harris S, Craze M, Newton J, Fisher M, Shima DT, Tozer GM, et al. Do antiangiogenic VEGF (VEGFxxxb) isoforms exist? A cautionary tale. PLoS One. 2012;7:e35231

112. Yamamoto $H$, Rundqvist $H$, Branco $C$, Johnson RS. Autocrine VEGF isoforms differentially regulate endothelial cell behavior. Front cell Dev Biol. 2016;4:99.

113. Guyot M, Pagès G. VEGF splicing and the role of VEGF splice variants: from physiological-pathological conditions to specific pre-mRNA splicing. Methods Mol Biol. 2015;1332:3-23.

114. Ladomery MR, Harper SJ, Bates DO. Alternative splicing in angiogenesis: the vascular endothelial growth factor paradigm. Cancer Lett. 2007;249:133-42.

115. Oltean S, Gammons M, Hulse R, Hamdollah-Zadeh M, Mavrou A, Donaldson $L$, et al. SRPK1 inhibition in vivo: modulation of VEGF splicing and potential treatment for multiple diseases. Biochem Soc Trans. 2012;40:831-5.

116. Giannakouros T, Nikolakaki E, Mylonis I, Georgatsou E. Serine-arginine protein kinases: a small protein kinase family with a large cellular presence. FEBS J. 2011;278:570-86.

117. Nowak DG, Amin EM, Rennel ES, Hoareau-Aveilla C, Gammons M Damodoran G, et al. Regulation of vascular endothelial growth factor (VEGF) splicing from pro-angiogenic to anti-angiogenic isoforms: a novel therapeutic strategy for angiogenesis. J Biol Chem. 2010;285:5532-40.

118. Barbagallo D, Caponnetto A, Brex D, Mirabella F, Barbagallo C, Lauretta G, et al. CircSMARCA5 regulates VEGFA mRNA splicing and angiogenesis in glioblastoma multiforme through the binding of SRSF1. Cancers. 2019;11:194.

119. Kikuchi R, Nakamura K, MacLauchlan S, Ngo DT-M, Shimizu I, Fuster JJ, et al. An antiangiogenic isoform of VEGF-A contributes to impaired vascularization in peripheral artery disease. Nat Med. 2014;20:1464-71.

120. Dou XQ, Chen XJ, Wen MX, Zhang SZ, Zhou Q, Zhang SQ. Alternative splicing of VEGFA is regulated by RBM10 in endometrial cancer. Kaohsiung J Med Sci. 2020;36:13-9.

121. Simons M, Gordon E, Claesson-Welsh L. Mechanisms and regulation of endothelial VEGF receptor signalling. Nat Rev Mol Cell Biol. 2016;17:611-25.

122. Thomas CP, Raikwar NS, Kelley EA, Liu KZ. Alternate processing of Flt1 transcripts is directed by conserved cis-elements within an intronic region of FLT1 that reciprocally regulates splicing and polyadenylation. Nucleic Acids Res. 2010;38:5130-40.
123. Ikeda T, Sun L, Tsuruoka N, Ishigaki Y, Yoshitomi Y, Yoshitake Y, et al Hypoxia down-regulates sFlt-1 (sVEGFR-1) expression in human microvascular endothelial cells by a mechanism involving mRNA alternative processing. Biochem J. 2011:436:399-407.

124. Boeckel JN, Guarani V, Koyanagi M, Roexe T, Lengeling A, Schermuly RT, et al. Jumonji domain-containing protein 6 (Jmjd6) is required for angiogenic sprouting and regulates splicing of VEGF-receptor 1. Proc Natl Acad Sci U S A. 2011;108:3276-81.

125. Eddy AC, Chapman H, Brown DT, George EM. Differential regulation of sFlt-1 splicing by U2AF65 and JMJD6 in placental-derived and endothelial cells. Biosci Rep. 2020;40:BSR20193252.

126. Abou Faycal C, Gazzeri S, Eymin B. A VEGF-A/SOX2/SRSF2 network controls VEGFR1 pre-mRNA alternative splicing in lung carcinoma cells. Sci Rep. 2019;9:336.

127. Pavlakovic H, Becker J, Albuquerque R, Wilting J, Ambati J. Soluble VEGFR-2: an antilymphangiogenic variant of VEGF receptors. Ann N Y Acad Sci. 2010; 1207(Suppl 1):E7-15.

128. Lampropoulou A, Ruhrberg C. Neuropilin regulation of angiogenesis. Biochem Soc Trans. 2014;42:1623-8.

129. Holzmann K, Grunt T, Heinzle C, Sampl S, Steinhoff H, Reichmann N, et al. Alternative splicing of fibroblast growth factor receptor lglll loops in cancer. J Nucleic Acids. 2012;2012:950508.

130. Ricol D, Cappellen D, El Marjou A, Gil-Diez-De-Medina S, Girault JM, Yoshida T, et al. Tumour suppressive properties of fibroblast growth factor receptor 2-IIIb in human bladder cancer. Oncogene. 1999;18:7234-43.

131. Oltean S, Sorg BS, Albrecht T, Bonano VI, Brazas RM, Dewhirst MW, et al. Alternative inclusion of fibroblast growth factor receptor 2 exon IIIc in dunning prostrate tumors reveals unexpected epithelial mesenchymal plasticity. Proc Natl Acad Sci U S A. 2006;103:14116-21.

132. Sonvilla G, Allerstorfer S, Heinzle C, Stättner S, Karner J, Klimpfinger M, et al. Fibroblast growth factor receptor 3-IIIc mediates colorectal cancer growth and migration. Br J Cancer. 2010;102:1145-56.

133. Pradella D, Naro C, Sette C, Ghigna C. EMT and stemness: flexible processes tuned by alternative splicing in development and cancer progression. Mol Cancer. 2017;16:8

134. Michelle L, Barbier J, Chabot B. hnRNP and hnRNP-like proteins in splicing control: molecular mechanisms and implication in human pathologies. In: Lorkovic JZ editor. RNA bind proteins. Landes Biosci. 2011:1-25.

135. Hovhannisyan RH, Carstens RP. Heterogeneous ribonucleoprotein $\mathrm{m}$ is a splicing regulatory protein that can enhance or silence splicing of alternatively spliced exons. J Biol Chem. 2007;282:36265-74.

136. Liang YC, Lin WC, Lin YJ, Lin JC. The impact of RNA binding motif protein 4regulated splicing cascade on the progression and metabolism of colorecta cancer cells. Oncotarget. 2015;6:38046-60.

137. Ke XS, Qu Y, Cheng Y, Li WC, Rotter V, Øyan AM, et al. Global profiling of histone and DNA methylation reveals epigenetic-based regulation of gene expression during epithelial to mesenchymal transition in prostate cells. BMC Genomics. 2010;11:669.

138. Du H, Zhao J, Hai L, Wu J, Yi H, Shi Y. The roles of vasohibin and its family members: beyond angiogenesis modulators. Cancer Biol Ther. 2017;18:827-32.

139. Martin JD, Seano G, Jain RK. Normalizing function of tumor vessels: progress, opportunities, and challenges. Annu Rev Physiol. 2019;81:505-34

140. Fagiani E, Christofori G. Angiopoietins in angiogenesis. Cancer Lett. 2013; 328:18-26.

141. Pankov R, Yamada KM. Fibronectin at a glance. J Cell Sci. 2002:115:3861-3.

142. Ventura E, Weller M, Macnair W, Eschbach K, Beisel C, Cordazzo C, et al. TGF$\beta$ induces oncofetal fibronectin that, in turn, modulates TGF- $\beta$ superfamily signaling in endothelial cells. J Cell Sci. 2018;131:jcs209619.

143. Bordeleau F, Califano JP, Abril YLN, Mason BN, LaValley DJ, Shin SJ, et al. Tissue stiffness regulates serine/arginine-rich protein-mediated splicing of the extra domain B-fibronectin isoform in tumors. Proc Natl Acad Sci U S A. 2015;112:8314-9.

144. Cai HP, Wang J, Xi SY, Ni XR, Chen YS, Yu YJ, et al. Tenascin-c mediated vasculogenic mimicry formation via regulation of MMP2/MMP9 in glioma. Cell Death Dis. 2019;10:879.

145. Dunleavey JM, Dudley AC. Vascular mimicry: concepts and implications for anti-angiogenic therapy. Curr Angiogenes. 2012;1:133-8.

146. Zagzag D, Friedlander DR, Dosik J, Chikramane S, Chan W, Greco MA, et al. Tenascin-C expression by angiogenic vessels in human astrocytomas and by human brain endothelial cells in vitro. Cancer Res. 1996:56:182-9. 
147. Keller KE, Kelley MJ, Acott TS. Extracellular matrix gene alternative splicing by trabecular meshwork cells in response to mechanical stretching. Investig Ophthalmol Vis Sci. 2007:48:1164-72.

148. Jensen MA, Wilkinson JE, Krainer AR. Splicing factor SRSF6 promotes hyperplasia of sensitized skin. Nat Struct Mol Biol. 2014;21:189-97.

149. Neri D, Bicknell R. Tumour vascular targeting. Nat Rev Cancer. 2005;5:436-46.

150. Li GJ, Yang Y, Yang GK, Wan J, Cui DL, Ma ZH, et al. Slit2 suppresses endothelial cell proliferation and migration by inhibiting the VEGF-notch signaling pathway. Mol Med Rep. 2017;15:1981-8.

151. Dunaway CM, Hwang Y, Lindsley CW, Cook RS, Wu JY, Boothby $M$, et al. Cooperative signaling between Slit2 and Ephrin-A1 regulates a balance between angiogenesis and angiostasis. Mol Cell Biol. 2011;31:404-16.

152. Wang B, Xiao $Y$, Ding BB, Zhang N, Bin YX, Gui L, et al. Induction of tumor angiogenesis by Slit-Robo signaling and inhibition of cancer growth by blocking Robo activity. Cancer Cell. 2003:4:19-29.

153. Lertkiatmongkol $P$, Liao D, Mei H, Hu Y, Newman PJ. Endothelial functions of platelet/endothelial cell adhesion molecule-1 (CD31). Curr Opin Hematol. 2016;23:253-9

154. Baldwin HS, Shen HM, Yan HC, DeLisser HM, Chung A, Mickanin C, et al. Platelet endothelial cell adhesion molecule-1 (PECAM-1/CD31): alternatively spliced, functionally distinct isoforms expressed during mammalian cardiovascular development. Development. 1994;120:2539-53.

155. Wang Y, Sheibani N. PECAM-1 isoform-specific activation of MAPK/ERKs and small GTPases: implications in inflammation and angiogenesis. J Cell Biochem. 2006;98:451-68.

156. DiMaio TA, Sheibani N. PECAM-1 isoform-specific functions in PECAM-1deficient brain microvascular endothelial cells. Microvasc Res. 2008;75:188-201.

157. Newman PJ, Newman DK. Signal transduction pathways mediated by PECA M-1: new roles for an old molecule in platelet and vascular cell biology. Arterioscler Thromb Vasc Biol. 2003;23:953-64.

158. Leroyer AS, Blin MG, Bachelier R, Bardin N, Blot-Chabaud M, Dignat-George F. CD146 (cluster of differentiation 146). Arterioscler Thromb Vasc Biol. 2019. 39:1026-33.

159. Yu Q, Toole BP. A new alternatively spliced exon between $v 9$ and $v 10$ provides a molecular basis for synthesis of soluble CD44. J Biol Chem. 1996;271:20603-7.

160. Rosen LS, Gordon MS, Robert F, Matei DE. Endoglin for targeted cancer treatment. Curr Oncol Rep. 2014;16:365.

161. Blanco FJ, Bernabeu C. Alternative splicing factor or splicing factor-2 plays a key role in intron retention of the endoglin gene during endothelial senescence. Aging Cell. 2011;10:896-907.

162. van Beijnum JR, Pieters W, Nowak-Sliwinska P, Griffioen AW. Insulin-like growth factor axis targeting in cancer and tumour angiogenesis - the missing link. Biol Rev Camb Philos Soc. 2017;92:1755-68.

163. Bogdanov VY, Balasubramanian V, Hathcock J, Vele O, Lieb M, Nemerson Y Alternatively spliced human tissue factor: a circulating, soluble, thrombogenic protein. Nat Med. 2003;9:458-62.

164. Bult CJ, Blake JA, Smith CL, Kadin JA, Richardson JE, Anagnostopoulos A, et al. Mouse genome database (MGD) 2019. Nucleic Acids Res. 2019;47:D801-6.

165. Ruzicka L, Bradford YM, Frazer K, Howe DG, Paddock H, Ramachandran S, et al. ZFIN, the zebrafish model organism database: updates and new directions. Genesis. 2015;53:498-509.

166. Keppetipola N, Sharma S, Li Q, Black DL. Neuronal regulation of pre-mRNA splicing by polypyrimidine tract binding proteins, PTBP1 and PTBP2. Crit Rev Biochem Mol Biol. 2012;47:360-78.

167. Mallinjoud P, Villemin J-P, Mortada H, Polay Espinoza M, Desmet F-O, Samaan S, et al. Endothelial, epithelial, and fibroblast cells exhibit specific splicing programs independently of their tissue of origin. Genome Res. 2014;24:511-21.

168. Caruso P, Dunmore BJ, Schlosser K, Schoors S, Dos Santos C, Perez-Iratxeta C, et al. Identification of MicroRNA-124 as a major regulator of enhanced endothelial cell glycolysis in pulmonary arterial hypertension via PTBP1 (Polypyrimidine tract binding protein) and pyruvate kinase M2. Circulation. 2017;136:2451-67.

169. Pen A, Moreno MJ, Martin J, Stanimirovic DB. Molecular markers of extracellular matrix remodeling in glioblastoma vessels: microarray study of laser-captured glioblastoma vessels. Glia. 2007;55:559-72.

170. Li H, Shen S, Ruan X, Liu X, Zheng J, Liu Y, et al. Biosynthetic CircRNA 001160 induced by PTBP1 regulates the permeability of BTB via the CircRNA_001160/miR-195-5p/ETV1 axis. Cell Death Dis. 2019;10:960.

171. Ferrarese R, Harsh GR IV, Yadav AK, Bug E, Maticzka D, Reichardt W, et al. Lineage-specific splicing of a brain-enriched alternative exon promotes glioblastoma progression. J Clin Invest. 2014;124:2861-76.
172. Shan H, Hou P, Zhang M, Li L, Pan Y, Chen F, et al. PTBP1 knockdown in renal cell carcinoma inhibits cell migration, invasion and angiogenesis in vitro and metastasis in vivo via the hypoxia inducible factor-1a pathway. Int J Oncol. 2018:52:1613-22.

173. Das S, Krainer AR. Emerging functions of SRSF1, splicing factor and oncoprotein, in RNA metabolism and cancer. Mol Cancer Res. 2014;12:1195-204.

174. Das S, Anczuków O, Akerman M, Krainer AR. Oncogenic splicing factor SRSF1 is a critical transcriptional target of MYC. Cell Rep. 2012;1:110-7.

175. Anczuków O, Rosenberg AZ, Akerman M, Das S, Zhan L, Karni R, et al. The splicing factor SRSF1 regulates apoptosis and proliferation to promote mammary epithelial cell transformation. Nat Struct Mol Biol. 2012;19:220-8.

176. Xu X, Yang D, Ding JH, Wang W, Chu PH, Dalton ND, et al. ASF/SF2regulated CaMKIIdelta alternative splicing temporally reprograms excitationcontraction coupling in cardiac muscle. Cell. 2005;120:59-72.

177. Li X, Wang J, Manley JL. Loss of splicing factor ASF/SF2 induces G2 cell cycle arrest and apoptosis, but inhibits internucleosomal DNA fragmentation. Genes Dev. 2005;19:2705-14

178. Ghigna C, Giordano S, Shen H, Benvenuto F, Castiglioni F, Comoglio PM, et al. Cell motility is controlled by SF2/ASF through alternative splicing of the Ron protooncogene. Mol Cell. 2005;20:881-90.

179. Maimon A, Mogilevsky M, Shilo A, Golan-Gerstl R, Obiedat A, Ben-Hur V, et al. Mnk2 alternative splicing modulates the p38-MAPK pathway and impacts Ras-induced transformation. Cell Rep. 2014;7:501-13.

180. Ben-Hur V, Denichenko P, Siegfried Z, Maimon A, Krainer A, Davidson B, et al. S6K1 alternative splicing modulates its oncogenic activity and regulates mTORC1. Cell Rep. 2013;3:103-15.

181. Amin EM, Oltean S, Hua J, Gammons MVR, Hamdollah-Zadeh M, Welsh Gl, et al. WT1 mutants reveal SRPK1 to be a downstream angiogenesis target by altering VEGF splicing. Cancer Cell. 2011;20:768-80.

182. Xie N, Chen M, Dai R, Zhang Y, Zhao H, Song Z, et al. SRSF1 promotes vascular smooth muscle cell proliferation through a $\Delta 133 \mathrm{p} 53 / \mathrm{EGR} 1 /$ KLF5 pathway. Nat Commun. 2017:8:16016.

183. Ule J, Ule A, Spencer J, Williams A, Hu JS, Cline M, et al. Nova regulates brain-specific splicing to shape the synapse. Nat Genet. 2005;37:844-52.

184. Giampietro C, Deflorian G, Gallo S, Di Matteo A, Pradella D, Bonomi S, et al. The alternative splicing factor Nova2 regulates vascular development and lumen formation. Nat Commun. 2015;6:8479.

185. Lother A, Bergemann S, Deng L, Moser M, Bode C, Hein L. Cardiac endothelial cell Transcriptome. Arterioscler Thromb Vasc Biol. 2018;38:566-74.

186. Baek S, Oh TG, Secker G, Sutton DL, Okuda KS, Paterson S, et al. The alternative splicing regulator Nova2 constrains vascular Erk signaling to limit specification of the lymphatic lineage. Dev Cell. 2019;49:279-292.e5.

187. Belloni E, Di Matteo A, Pradella D, Vacca M, Wyatt CDR, Alfieri R, et al. Gene expression profiles controlled by the alternative splicing factor Nova2 in endothelial cells. Cells. 2019;8:1498.

188. Gallo S, Arcidiacono MV, Tisato V, Piva R, Penolazzi L, Bosi C, et al. Upregulation of the alternative splicing factor NOVA2 in colorectal cancer vasculature. Onco Targets Ther. 2018;11:6049-56.

189. Konieczny P, Stepniak-Konieczna E, Sobczak K. MBNL proteins and their target RNAs, interaction and splicing regulation. Nucleic Acids Res. 2014;42: 10873-87.

190. Schiano C, Rienzo M, Casamassimi A, Soricelli A, Napoli C. Splicing regulators in endothelial cell differentiation. J Cardiovasc Med. 2017:18:742-9.

191. Zhang J, Zheng Z, Wu M, Zhang L, Wang J, Fu W, et al. The natural compound neobractatin inhibits tumor metastasis by upregulating the RNA-binding-protein MBNL2. Cell Death Dis. 2019;10:554.

192. Du J, Aleff RA, Soragni E, Kalari K, Nie J, Tang X, et al. RNA toxicity and missplicing in the common eye disease fuchs endothelial corneal dystrophy. J Biol Chem. 2015;290:5979-90.

193. Govindaraju S, Lee BS. Adaptive and maladaptive expression of the mRNA regulatory protein HuR. World J Biol Chem. 2013;4:111-8.

194. Chang SH, Elemento O, Zhang J, Zhuang ZW, Simons M, Hla T. ELAVL1 regulates alternative splicing of elF4E transporter to promote postnatal angiogenesis. Proc Natl Acad Sci U S A. 2014;111:18309-14.

195. Chang SH, Lu YC, Li X, Hsieh WY, Xiong Y, Ghosh M, et al. Antagonistic function of the RNA-binding protein HuR and miR-200b in posttranscriptional regulation of vascular endothelial growth factor-a expression and angiogenesis. J Biol Chem. 2013;288:4908-21.

196. Kurosu T, Ohga N, Hida Y, Maishi N, Akiyama K, Kakuguchi W, et al. HuR keeps an angiogenic switch on by stabilising mRNA of VEGF and COX-2 in tumour endothelium. Br J Cancer. 2011;104:819-29. 
197. Damianov A, Ying Y, Lin CH, Lee JA, Tran D, Vashisht AA, et al. Rbfox proteins regulate splicing as part of a large multiprotein complex LASR. Cell. 2016;165:606-19.

198. Mavrou A, Oltean S. SRPK1 inhibition in prostate cancer: a novel antiangiogenic treatment through modulation of VEGF alternative splicing. Pharmacol Res. 2016;107:276-81.

199. Kaida D, Motoyoshi H, Tashiro E, Nojima T, Hagiwara M, Ishigami K, et al. Spliceostatin a targets SF3b and inhibits both splicing and nuclear retention of pre-mRNA. Nat Chem Biol. 2007:3:576-83.

200. Chen C, Zhao S, Karnad A, Freeman JW. The biology and role of CD44 in cancer progression: therapeutic implications. J Hematol Oncol. 2018;11:64

201. Orian-Rousseau V, Ponta H. Perspectives of CD44 targeting therapies. Arch Toxicol. 2015;89:3-14.

202. Maruyama-Takahashi K, Shimada N, Imada T, Maekawa-Tokuda Y, Ishii T, Ouchi J, et al. A neutralizing anti-fibroblast growth factor (FGF) 8 monoclonal antibody shows anti-tumor activity against FGF8b-expressing LNCaP xenografts in androgen-dependent and -independent conditions. Prostate. 2008;68:640-50.

203. Lin X, Song L, He D, Zeng X, Wu J, Luo W, et al. An FGF8b-mimicking peptide with potent antiangiogenic activity. Mol Med Rep. 2017;16:894-900.

204. Giacomini A, Matarazzo S, Pagano K, Ragona L, Rezzola S, Corsini M, et al. A long pentraxin-3-derived pentapeptide for the therapy of FGF8b-driven steroid hormone-regulated cancers. Oncotarget. 2015;6:13790-802.

205. Moschetta M, Pretto F, Berndt A, Galler K, Richter P, Bassi A, et al. Paclitaxel enhances therapeutic efficacy of the F8-IL2 immunocytokine to EDAfibronectin-positive metastatic human melanoma xenografts. Cancer Res. 2012;72:1814-24.

206. Frey K, Schliemann C, Schwager K, Giavazzi R, Johannsen M, Neri D. The immunocytokine F8-IL2 improves the therapeutic performance of sunitinib in a mouse model of renal cell carcinoma. J Urol. 2010;184:2540-8.

207. Johannsen M, Spitaleri G, Curigliano G, Roigas J, Weikert S, Kempkensteffen C, et al. The tumour-targeting human L19-IL2 immunocytokine: preclinical safety studies, phase I clinical trial in patients with solid tumours and expansion into patients with advanced renal cell carcinoma. Eur J Cancer. 2010;46:2926-35.

208. Eigentler TK, Weide B, De Braud F, Spitaleri G, Romanini A, Pflugfelder A, et al. A dose-escalation and signal-generating study of the immunocytokine L19-IL2 in combination with dacarbazine for the therapy of patients with metastatic melanoma. Clin Cancer Res. 2011;17:7732-42.

209. Saw PE, Kim S, Lee IH, Park J, Yu M, Lee J, et al. Aptide-conjugated liposome targeting tumor-associated fibronectin for glioma therapy. J Mater Chem B. 2013;1:4723-6.

210. Saw PE, Park J, Lee E, Ahn S, Lee J, Kim H, et al. Effect of PEG pairing on the efficiency of cancer-targeting liposomes. Theranostics. 2015;5:746-54.

211. Catania C, Maur M, Berardi R, Rocca A, Di Giacomo AM, Spitaleri G, et al. The tumor-targeting immunocytokine F16-IL2 in combination with doxorubicin: dose escalation in patients with advanced solid tumors and expansion into patients with metastatic breast cancer. Cell Adhes Migr. 2015;9:14-21.

212. Mavrou A, Brakspear K, Hamdollah-Zadeh M, Damodaran G, Babaei-Jadidi R, Oxley J, et al. Serine-arginine protein kinase 1 (SRPK1) inhibition as a potential novel targeted therapeutic strategy in prostate cancer. Oncogene. 2015;34:4311-9.

213. Li X, Song J, Liu J, Wu S, Wang L, Gong L, et al. Serine-arginine protein kinase 1 is associated with breast cancer progression and poor patient survival. Med Oncol. 2014;31:83.

214. Havens MA, Hastings ML. Splice-switching antisense oligonucleotides as therapeutic drugs. Nucleic Acids Res. 2016;44:6549-63.

215. Orian-Rousseau V, Sleeman J. CD44 is a multidomain signaling platform that integrates extracellular matrix cues with growth factor and cytokine signals. Adv Cancer Res. 2014;123:231-54.

216. Orend G, Saupe F, Schwenzer A, Midwood K. The extracellular matrix and cancer : regulation of tumor cell biology by tenascin-C. iConcept Press (May 5 2014).

\section{Publisher's Note}

Springer Nature remains neutral with regard to jurisdictional claims in published maps and institutional affiliations.

\section{Ready to submit your research? Choose BMC and benefit from:}

- fast, convenient online submission

- thorough peer review by experienced researchers in your field

- rapid publication on acceptance

- support for research data, including large and complex data types

- gold Open Access which fosters wider collaboration and increased citations

- maximum visibility for your research: over $100 \mathrm{M}$ website views per year

At BMC, research is always in progress.

Learn more biomedcentral.com/submissions 